\title{
1 IgM Natural Antibodies Bind HLA-E-Leader Peptide Complexes and Modulate NK
}

\section{Cell Cytotoxicity}

4 Dapeng Li ${ }^{1, \#}$, Simon Brackenridge ${ }^{4, \#}$, Lucy C. Walters ${ }^{4, \#}$, Karl Harlos ${ }^{5}$, Daniel Rozbesky ${ }^{5,6}$, Derek

5 W. Cain ${ }^{1,2}$, Kevin Wiehe ${ }^{1,2}$, Richard M. Scearce ${ }^{1}$, Maggie Barr ${ }^{1}$, Zekun Mu${ }^{1}$, Robert Parks ${ }^{1}$, Max

6 Quastel $^{4}$, Robert J. Edwards ${ }^{1,2}$, S. Munir Alam ${ }^{1,2}$, Kevin O. Saunders $^{1,4}$, Persephone Borrow $^{4}$, E.

7 Yvonne Jones ${ }^{5}$, Geraldine M. Gillespie ${ }^{4,{ }^{*}}$, Andrew J. McMichael ${ }^{4,{ }^{*}}$, Barton F. Haynes ${ }^{1,3,{ }^{*}}$

$9{ }^{1}$ Duke Human Vaccine Institute, Duke University School of Medicine, Durham, NC 27710, USA

$10{ }^{2}$ Department of Medicine, Duke University School of Medicine, Durham, NC 27710, USA

$11{ }^{3}$ Department of Immunology, Duke University School of Medicine, Durham, NC 27710, USA

$12{ }^{4}$ Nuffield Department of Clinical Medicine, University of Oxford, Oxford, OX3 7FZ, UK

13 DDivision of Structural Biology, Wellcome Centre for Human Genetics, University of Oxford,

14 Oxford, OX3 7BN, UK

$15{ }^{6}$ Department of Cell Biology, Charles University, Prague, 12800, Czech Republic

$16 \quad$ \#Authors contributed equally

17 *Address correspondence to geraldine.gillespie@ndm.ox.ac.uk, 


\section{ABSTRACT (147 words)}

21 The non-classical class Ib molecule human leukocyte antigen E (HLA-E) has limited

22 polymorphism and can bind HLA class la leader sequence peptides (VL9). HLA-E-VL9

23 complexes interact with the natural killer (NK) cell inhibitory receptor NKG2A/CD94 and regulate

24 NK cell-mediated cytotoxicity. Here we report a murine HLA-E-VL9-specific IgM monoclonal

25 antibody $3 \mathrm{H} 4$ that enhanced killing of HLA-E-VL9-expressing target cells by a NKG2A ${ }^{+}$NK cell

26 line, most likely due to steric clashes between 3H4 and CD94/NKG2A when docked on the

27 HLA-E-VL9 surface as determined by a $1.8 \AA$ co-complex crystal structure. Key 3H4-mediated

28 contacts with HLA-E-VL9 were generated by germline-encoded CDR-H3 residues. Human IgM

29 HLA-E-VL9 reactive antibodies could also be isolated from CD10/CD27 naïve B cells; these

30 antibodies also recognized microbiome-derived peptides presented by HLA-E. Thus, a subset of

31 natural antibodies that recognize VL9-bound HLA-E exist as part of the normal Ig repertoire with

32 capacity to regulate NK cell function. 


\section{INTRODUCTION}

Natural killer (NK) cells play critical roles in immune surveillance by discriminating non-self from self, and function as effector cells by killing non-self malignant or pathogen-infected cells and producing inflammatory cytokines (Chiossone et al., 2018; Raulet, 2006; Yokoyama and

Kim, 2006). Specific recognition of non-self by NK cells relies on a series of activating and inhibitory receptors, including the killer immunoglobulin-like receptor (KIR) family and the

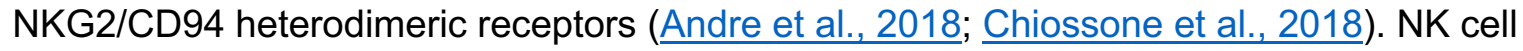

41 inhibitory receptors ligate human lymphocyte antigen (HLA) or major histocompatibility complex

$42(\mathrm{MHC})$ class I molecules expressed on healthy cells as self. Conversely, cells lacking MHC class I are recognized by NK cells as "missing-self" and are sensitive to NK cell-mediated killing

44 (Ljunggren and Karre, 1985, 1990). In humans, KIRs recognize classical human HLA class la molecules (Colonna and Samaridis, 1995; Karlhofer et al., 1992; Pende et al., 2019), whereas the inhibitory NKG2A/CD94 heterodimeric receptor interacts with the non-classical HLA class lb molecule HLA-E and is balanced by an activating receptor NKG2C/CD94 (Braud et al., 1997; Braud et al., 1998; Brooks et al., 1997). While KIRs expression is heterogeneous,, NKG2A/CD94 is expressed on $\sim 40 \%$ of human NK cells (Andre et al., 1999; Mahapatra et al., 2017; Pende et al., 2019). Similarly, unlike classical HLA class I molecules, HLA-E has limited

51 polymorphism with only two predominant expressed variants HLA-E*01:01 and HLA-E*01:03

52 that differ only in residue 107, which is outside the peptide-binding groove (Kraemer et al.,

53 2014). The NKG2A/CD94/HLA-E pathway is considered as an important immune checkpoint

54 target and has recently become a focus for NK cell-based immunotherapeutic strategies ( $\underline{\text { Hu et }}$

55 al., 2019; Kim et al., 2019; Souza-Fonseca-Guimaraes et al., 2019). A subset of CD8+ T cells

56 also express NKG2A/CD94, and inhibition of NKG2A/CD94 - HLA-E interaction similarly has

57 application in CD8+ T cell-based immunotherapy (Andre et al., 2018; van Montfoort et al.,

58 2018). 
HLA-E engages with NKG2A/CD94 via a restricted subset of peptides VMAPRT(L/V)

$(\mathrm{V} / \mathrm{L} / \mathrm{I} / \mathrm{F}) \mathrm{L}$ (designated $\mathrm{VL9}$ ) that derive from the leader sequence of HLA-A, $-\mathrm{C},-\mathrm{G}$ and a third of

61 HLA-B molecules (Braud et al., 1997; Braud et al., 1998; Lee et al., 1998a; Lee et al., 1998b).

62 HLA-E binds VL9 peptides, which stabilize HLA-E surface expression (Braud et al., 1997; Braud

63 et al., 1998) on healthy host cells in which HLA-la expression is not perturbed and initiate

64 recognition by NKG2A/CD94 or NKG2C/CD94 on NK cells. The binding affinity of HLA-E-VL9

65 peptide complexes for NKG2A/CD94 is greater than that for NKG2C/CD94, such that the

66 inhibitory signal dominates to suppress aberrant NK cell-mediated cytotoxicity as well as

67 cytokine production (Aldrich et al., 1994; Braud et al., 1998; Kaiser et al., 2008; Llano et al.,

1998; Rolle et al., 2018). In addition, HLA-E and its murine or rhesus macaque homologs, is

capable of binding to a range of other host peptides and pathogen-derived peptides, including heat-shock protein 60 (Hsp60)-derived peptides (Michaelsson et al., 2002), Mycobacterium

71 tuberculosis (Mtb) peptides (Joosten et al., 2010; van Meijgaarden et al., 2015), and simian

72 immunodeficiency virus (SIV) Gag peptides (Hansen et al., 2016), though unusually with a lower

73 affinity than VL9 (Walters et al., 2020). However, only VL9 peptide-loaded HLA-E can engage

74 CD94/NKG2A and protect cells from NK cell cytotoxicity (Kraemer et al., 2015; $\underline{\text { Michaelsson et }}$

75 al., 2002; Sensi et al., 2009). Hence, leader sequence VL9 peptides are essential not only for stabilizing HLA-E surface expression but also for determining the role of HLA-E/NKG2A/CD94 pathway in regulating NK cell self-recognition. However, it remains unclear if interruption of this pathway by specifically targeting HLA-E-peptide complexes can enhance NK cell activity.

Natural antibodies are immunoglobulins that are present prior to simulation by cognate

80 antigen, and provide the first line of defence against bacterial, fungal and viral infections

81 (Holodick et al., 2017). They also suppress autoimmune, inflammatory and allergic responses,

82 protect from atherosclerotic vascular injury, and mediate apoptotic cell clearance (New et al.,

83 2016). Natural antibodies are generally near germline in sequence, have repertoire skewing of 
$84 \lg \mathrm{M}, \lg \mathrm{A}$ or $\lg \mathrm{E}$ isotype, and respond to antigens with T cell independence (

85 2017). However, specific roles in regulation of natural killer (NK) cell functions are unknown.

Here, we define a mechanism of natural antibody modulation of NK cell killing whereby a

murine IgM monoclonal antibody (mAb) 3H4 bound to HLA-E-VL9 on target cells and enhanced

NK cytotoxicity of a NKG2A+ NK cell line. X-ray crystallographic analysis of an HLA-E-VL9/3H4 antigen-binding fragment (Fab) co-complex indicated that due to steric clashes, $3 \mathrm{H} 4$ and

CD94/NKG2A cannot simultaneously bind to what are essentially overlapping recognition

surfaces on HLA-E-VL9. Key Ig V(D)J residues in the 3H4-HLA-E-VL9 binding interface were germline-encoded. Similarly, human HLA-E-VL9-reactive, near-germline IgMs were isolated from the naïve B cell repertoire that recognized microbiome VL9-like peptides presented by HLA-E. Thus, a subset of natural IgM HLA-E-VL9 antibodies exist in vivo that have the potential to regulate NK cell cytotoxicity.

\section{RESULTS}

Isolation of an HLA-E-VL9-specific mAb 3H4 from immunized transgenic mice

With the original intention of raising monoclonal antibodies to the HIV-1 Gag peptide peptides identified by Hansen et al., 2016), we immunized human HLA-B27/ß2-microglobulin (B2M) transgenic mice (Taurog et al., 1990) (Figures S1A-B) with 293T cells transfected with surface-expressed single chain HLA-E-RL9HIV complexes (Yu et al., 2002) (Figure 1A and S1C-D). We produced hybridomas, and culture supernatants were screened for binding on a panel of 293T cells transfected with single chain HLA-E-RL9HIV peptide complexes, or with single chain HLA-E-VL9 peptide complexes as a control. Unexpectedly, we isolated a subset of

107 antibodies that specifically reacted with HLA-E-VL9 peptide, the most potent of which was the 108 IgM mAb 3H4. Unlike the well-characterized pan-HLA-E mAb 3D12 (Marin et al., 2003), 3H4 109 reacted specifically with HLA-E-VL9 (VMAPRTLVL) and not with control, non-VL9 HLA-E- 
peptide complexes (Figure 1B). Mab 3H4 also bound to VL9 peptide-pulsed HLA-class I

111 negative K562 cells transfected with HLA-E (Lampen et al., 2013) (Figure 1C). Moreover, 3H4

112 bound to soluble HLA-E refolded with synthetic VL9 peptide in both ELISA (Figure 1D) and

113 surface plasmon resonance (SPR) assays (Figure 1E).

\section{HLA-E-VL9-specific mAb $3 \mathrm{H} 4$ is a minimally mutated pentameric IgM}

Sequence analysis of $3 \mathrm{H} 4 \mathrm{mAb}$ revealed $1.04 \%$ heavy chain variable region $\left(\mathrm{V}_{\mathrm{H}}\right)$ and

\section{H4 IgM enhances NK cell cytotoxicity against HLA-E-VL9-expressing target cells}

Given the suppressive role of the HLA-E-VL9/NKG2A/CD94 pathway in NK cell function, we

131 2B). Next, we engineered the $3 \mathrm{H} 4$ variable regions into a human IgG2 $\sigma$ backbone (Saunders,

132 2019) (Figure S5). The 3H4-human IgG retained binding specificity for HLA-E-VL9, but showed

133 no cytotoxicity enhancement of NK cells (Figure 2 C). In addition, we tested a combination of

$1343 \mathrm{H} 4$ with the NKG2A specific antibody, Z199. While blocking NKG2A enhanced NK killing

135 against HLA-E-VL9 expressing cells (Figure 2D), no further elevated killing was observed when 
combining 3H4 with Z199 (Figure 2E), suggesting that killing enhancement was maximal with 3H4 alone. These data demonstrated that HLA-E-VL9-specific mAb 3H4 could enhance the killing capacity of NKG2A+ NK cells, and this immunoregulatory role of $3 \mathrm{H} 4$ was dependent on its IgM pentameric form, probably due to higher avidity binding.

\section{$3 \mathrm{H} 4 \mathrm{Ig}$ M recognizes the $\alpha 1 / \alpha 2$ domain of HLA-E and N-terminus of the VL9 peptide}

To map the epitope on the HLA-E-VL9 complex recognized by $3 \mathrm{H} 4$, we tested $3 \mathrm{H} 4$ binding

143 to VL9 peptide presented by HLA-E, the rhesus ortholog Mamu-E, as well as two HLA-E/Mamu-

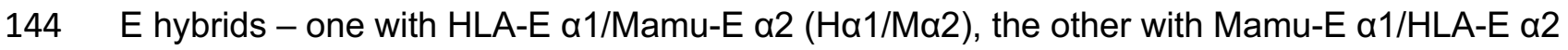

145 (Ma1/Ha2). 3H4 did not bind to Mamu-E/VL9 nor Ha1/Ma2-VL9, and its staining of cells

expressing Ma1/Ha2-VL9 was weak (Figure $3 A$ ), suggesting that $3 \mathrm{H} 4$ recognition involves

\section{Co-complex crystal structure of a 3H4 Fab bound to HLA-E-VL9}

We obtained a co-complex crystal structure of the 3H4 Fab bound to VL9 peptide-loaded

158 HLA-E, which packed in the C2 space group and diffracted to $1.8 \AA$ (Table S2). Although two

159 copies of the co-complex were present in the asymmetric unit, a single copy constitutes the

160 focus of further discussion here since root-mean-square deviation (RMSD) calculations from

161 Ca-atom pairwise alignment of the two copies indicated minimal repositioning of interfacing 
residues at the HLA-E-3H4 binding site (Table S3). Additionally, pairwise alignment with the previously published non-receptor-bound HLA-E coordinates (PDB: 1MHE) (O'Callaghan et al., 1998) revealed minimal structural changes in HLA-E upon 3H4 engagement (Table S3B).

$3 \mathrm{H} 4$ docked onto the $\mathrm{N}$-terminal region of the HLA-E-peptide-binding groove making contacts with both $\alpha$-helices of the HLA-E heavy chain in addition to residues 1-4 of the VL9 peptide (Figures 4A-B). The 3H4-HLA-E interface was mainly mediated via electrostatic interactions and was dominated by the $3 \mathrm{H} 4 \mathrm{VH}$ chain segment which created a total buried surface area of $1109.4 \AA^{2}$ and formed ten hydrogen bonds ( $\mathrm{H}$-bonds) and three salt bridges with HLA-E residues of the a1-helix and one H-bond with T163 of the HLA-E a2-helix. By contrast,

171 the smaller $3 \mathrm{H} 4 \mathrm{VL}$ chain-HLA-E interface buried $522.8 \AA^{2}$ and involved only three inter-

172 molecular H-bonds and three salt bridges (Tables S3 and S4). Superposition of the 3H4-HLA-

173 E-VL9 co-complex with a previously published HLA-E-bound CD94/NKG2A structure (Kaiser et

174 al., 2008; Petrie et al., 2008) revealed steric clashes between the VH and VL domains of 3H4 175 and the CD94 and NKG2A subdomains, respectively (Figures 4C-D). Moreover, seven HLA-E 176 heavy chain residues (positions 58, 59, 62, 63 on the $\alpha 1$ helix and 162, 163 and 167 on the $\alpha 2$ 177 helix) are shared between the 3H4-HLA-E and CD94/NKG2A-HLA-E footprints (Figures 4E-F). 178 Such steric clashes and overlapping footprints suggest simultaneous docking of these two HLA179 E binding partners, 3H4 and NKG2A/CD94, would be disallowed.

\section{Germline-encoded residues are critical for $3 \mathrm{H} 4$ contact with both HLA-E and VL9 peptide}

Remarkably, all four of the 3H4-derived residues that interface with the VL9 peptide (Y97,

184 germline-encoded. This 3H4-VL9 interface is characterized by weak Van der Waals and

185 hydrophobic contacts, such as those mediated between Y100B (3H4) and V1 or P4 (VL9)

186 (Figure 4G). Further, the positioning of the Y100B (3H4) side chain directly above V1 (VL9) in

187 part explains the preference for small side chains at this position of the peptide and the dramatic 
reductions in $3 \mathrm{H} 4$ binding to HLA-E bound to VL9 variants with larger residues such as $\mathrm{H}$ or $\mathrm{F}$ at position 1 (Figure 3C). Distinctive shape complementarity is also observed at the 3H4-VL9 interface with the side chains of S100 and S100A (3H4) wrapping around the cyclic side chain of P4 (VL9).

The germline-encoded VH CDR3 D-junction residues that form the 3H4-VL9 interface (Y97, S100, S100A and Y100B), also mediate key contacts with the HLA-E heavy chain. The surface

194 loop (residues A93-V102) containing these germline-encoded residues sweeps across the HLA195 E-peptide-binding groove forming $\mathrm{H}$-bonds with both the $\alpha 1$ and $\alpha 2$ helices; T163 of the HLA-E 196 a2 helix forms a H-bond with S100 (3H4), and R62 of the HLA-E a1-helix forms two H-bonds with the $\mathrm{Y} 100 \mathrm{~B}(3 \mathrm{H} 4)$ mainchain and an additional $\mathrm{H}$-bond with the main chain of S100A (3H4) (Figure 4H). Moreover, Y100B (3H4) is involved in multiple polar pi stacking interactions. Not only is the Y100B side chain sandwiched between R62 and W167 of the HLA-E $\alpha 1$ and $\alpha 2$ helices, respectively, R62 (HLA-E a1) is also positioned between the aromatic rings of Y100B and W100D of the VH CDR3 domain.

Key contacts outside the germline-encoded CDR3 D-junction region are also formed at the 3H4 VH-HLA-E or 3H4 VL-HLA-E interfaces. For 3H4 HC, the VH CDR2 region (residues I51T57) is positioned above the HLA-E a1-helix where a string of inter-molecular H-bonds are

205 formed involving G56 and N54 of the VH CDR2 in addition to D50, Q61 and K64 of the 206 framework VH chain region (Figure 4H). Critically, R65 of the HLA-E a1-helix forms four H207 bonds with the $3 \mathrm{H} 4 \mathrm{VH}$ and also mediates polar pi stacking interactions with $\mathrm{W} 100 \mathrm{D}$ of the $\mathrm{VH}$ 208 CDR3 loop. For 3H4 LC, D92 and E93 of the VL CDR3 loop H-bond with K170 of the HLA-E a2209 helix and N30 of the VL CDR1 loop forms an H-bond with the a2-helix residue, E166, of HLA-E 210 (Figure 4I). It is noteworthy that the four key interfacing residues of the 3H4 VH CDR3 D211 junction (Y97, S100, S100A and Y100B) are germline-encoded (Figures 4J). Since these 212 residues interface with both the HLA-E heavy chain and VL9 peptide, the B cell receptor 
213 germline component plays a central role in the recognition of VL9-bound HLA-E complexes by

$2143 \mathrm{H} 4$.

215

\section{Germline-encoding HLA-E-VL9-specific antibodies exist in healthy humans}

That HLA-E-VL9-specific antibodies were isolated from mice immunized with an unrelated peptide antigen (RL9HIV) implied that antibody 3H4 might be derived from the natural $\mathrm{B}$ cell pool rather than induced by immunization. Therefore, we assessed binding of HLA-E-VL9 fluorescent tetramers to B cells from naïve HLA-B27/ß2M TG mice and B6 mice, and found that

221 HLA-E-VL9-binding B cells existed in unimmunized mice (Figure S7). Additionally, all HLA-E-

222 VL9-specific antibodies were minimally mutated IgM antibodies (Table S1). These findings raised the hypothesis that HLA-E-VL9-specific antibodies were natural antibodies in mice.

Table S5). We isolated 56 HLA-E-VL9-specific antibodies (Figure 5B, Table S6) that specifically reacted with HLA-E-VL9 complexes (Figures S9-S10). By performing more in-depth analysis of the binding profiles of four representative antibodies - CA123, CA133, CA143 and CA147, we found that these antibodies exhibited distinct binding specificities to VL9 peptide variants (Figure 5C) in addition to differential cross-reactivities with rhesus Mamu-E-VL9 or mouse Qa-1-VL9 complexes (Figure S11A-D). These data suggested that BCRs with diverse recognition patterns on the HLA-E-VL9 complex are present in uninfected humans. 
memory cells, demonstrating that BCRs specifically targeting HLA-E-VL9 peptide existed in the naïve B cell repertoire of healthy humans.

\section{$V_{H} / V_{L}$ gene usage of HLA-E-VL9-specific antibodies}

Natural antibodies demonstrate Ig repertoire skewing (

244 2016). To characterize the human antibody gene usage of HLA-E-VL9 antibodies, we analyzed

245 the paired heavy chain and light chain gene sequences of 56 human HLA-E-VL9 antibodies,

246 and found 1 multiple-member clone containing 6 antibodies in donor LP021 (Kepler et al., 2014)

247 (Table S7). Next, we compared the 51 HLA-E-VL9-specific B cell clones with a reference

248 human antibody repertoire (DeKosky et al., 2015). Over 45\% of the heavy chain variable region

$249\left(V_{H}\right)$ genes were VH3-21 or VH3-11 in HLA-E-VL9 antibodies, whereas less than 7\% of the

250 control B cells used these two genes (Figure 6A and Table S6). HLA-E-VL9 antibodies light

251 chain variable region $\left(\mathrm{V}_{\mathrm{K}} \mathrm{N}_{\lambda}\right)$ also preferentially utilized IGKV3-15, IGKV1-39 and IGKV3-11

252 genes compared to controls (Figure 6B and Table S6). No J chain gene usage preference was

253 observed (Figure S12). Moreover, HLA-E-VL9 antibodies showed a trend to have shorter heavy

254 chain complementarity determining region 3 (CDR3) lengths than the reference antibodies

255 (Figure 6C), while no difference was observed for light chain CDR3 (Figure 6D). Given HLA-E-

256 VL9 antibodies were all IgMs primarily from naïve or immature B cells, we compared the

257 mutation frequencies of 51 clones with a reference human antibody repertoire containing both

258 naïve and antigen-experienced antibodies (DeKosky et al., 2016). Both heavy and light chain

259 variable region genes exhibited low somatic mutation rates that were similar to naïve B cell

260 controls (Figures 6E-F). Thus, human HLA-E-VL9-specific antibodies were IgM, minimally

261 mutated and displayed skewed usage of VH3-21 and VH3-11 VHs and IGKV3-15, IGKV1-39

262 and IGKV3-11 VLs. 
HLA-E-VL9-specific mAbs recognize microbiome-derived VL9-like peptides presented by HLA-E

We identified microbiome-derived VL9-like peptides from the NCBI microbiome database predicted by NetMHC to have HLA-E binding capacity (Andreatta and Nielsen, 2016; Nielsen et

al., 2003) (Table S7). Eight peptides with the highest HLA-E binding scores were synthesized as 9 amino acid peptides, incubated with K562-E cells, and tested for mAb 3H4 HLA-E-VL9specific antibody binding. Seven out of eight microbiome sequence-derived peptides showed strong HLA-E binding as indicated by the ability to stabilize and upregulate HLA-E expression, as read out by staining with HLA-E reactive antibody, 3D12 (Figures 7 and S13A). Notably, peptides with sequences very closely related to VL9 (VMAPRTLLL), VMPPRALLL (from

277 formosensis-derived peptide VMAPRTKLL bound to HLA-E (Lin et al., 2013) (Figures 7 and peptides may be one type of antigen capable of stimulating B cells with HLA-E-VL9 peptide

281 specificity in vivo.

\section{DISCUSSION}

In this study, we have isolated and characterized antibodies reactive with HLA-E-VL9 peptide complexes, and found these antibodies were derived from the naïve IgM B cell BCR repertoire in mice as well as in non-immunized, HCMV seronegative male humans. While more

287 than $80 \%$ of the HLA-E-VL9 reactive B cells were immature or naïve, a few showed a memory 288 or plasmablast phenotype. However, somatic mutations were minimal and the affinity was low.

289 The lack of class switching in HLA-E-VL9-specific antibodies may reflect self-tolerance of CD4 T 
cells and a lack of help for maturation of these antibodies. While the mouse antibodies were selected in the setting of HLA-E-unrelated peptide immunizations, they were minimally mutated IgM antibodies, as were most of the antibodies isolated from un-infected human males.

293 Structural analysis of the HLA-E-VL9:3H4 Fab co-complex revealed that the 3H4 heavy chain 294 made key contacts with HLA-E and the VL9 peptide using germline-encoded residues in the 295 CDR-H3 (D) region (Figure 4J). However, 3H4 is a mouse antibody reacting with human HLA-

296 E-VL9. The HLA-E equivalent in C57BL/6xSJL mice is Qa1b which presents the very similar 297 class la signal peptide ‘Qdm' AMAPRTLLL. Whilst 3H4 recognizes that peptide bound to HLA-E, 298 it does not bind to that peptide in Qa1b (Figure S6B). However, HLA-E-VL9-specific antibodies 299 were identified in the naïve B cell pool of healthy humans, so the question arises as to whether 300 such B cells, or the antibodies they can produce, play an important immunoregulatory role in 301 humans. If so, this might provide the selective force to maintain these enriched $V$ genes in the 302 germline. Indeed, we demonstrated proof of concept that the 3H4 IgM HLA-E-VL9 antibody 303 could enhance NK cytotoxicity of NKG2A+ NK cells.

Autoantibodies to HLA-la (Alberu et al., 2007; Morales-Buenrostro et al., 2008) and HLA-E heavy chains (Ravindranath et al., 2010a; Ravindranath et al., 2010b) have been detected in non-alloimmunized males, and contribute to allograft damage (iickey et al., 2016; $\underline{\text { McKenna et }}$ al., 2000). It has been suggested that the HLA-E antibodies in non-alloimmunized humans could be elicited by autoantigens derived from viral, bacterial, or environmental agents cross-reactive with HLAs, or soluble HLA-E heavy chains that become immunogenic without the $\beta 2 \mathrm{M}$ subunit

311 Viruses, bacteria and other microbes could be the stimuli of such innate-adaptive immune 312 interaction. The best known example is human cytomegalovirus (HCMV) that encodes the VL9 313 sequence VMAPRTLIL in the leader sequence of its UL40 gene. This peptide is processed in a 314 TAP independent manner and presented bound to HLA-E at the cell surface to inhibit NK cell 315 killing and evade innate immune responses (Tomasec et al., 2000). This has not been reported 
316 to elicit antibody responses, but HLA-E-UL40 peptide-specific T cells have been described

317 when the limited polymorphism in the HLA A, B and C sequences mismatches that of the virus

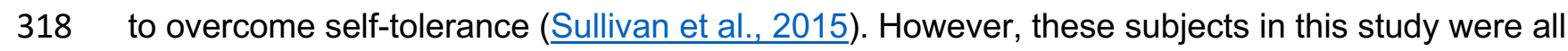

319 HCMV seronegative, ruling out the possibility that these antibodies were HCMV-induced.

320 Similarly, that they were male excluded pregnancy induced priming. A recent study found that

321 mouse gut microbial antigens shaped the BCR repertoire by contributing to BCR selection and

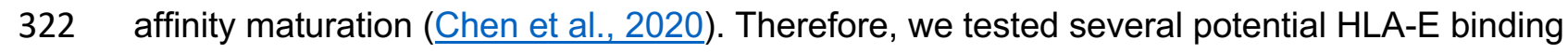

323 peptides, with sequence similarities to VL9, derived from the human microbiome. Three of our

324 HLA-E-VL9 antibodies recognized a subset of these HLA-E-presented microbiome-derived VL9-

325 like peptides. These data imply that human microbial peptides could also be presented by HLA-

326 E, interact with HLA-E-VL9-bound naïve BCRs, and trigger expansion of B cells that express

327 HLA-E-VL9-specific BCRs.

Harnessing NK cells to attack tumor cells has emerged as an attractive strategy for cancer

immunotherapies (Guillerey et al., 2016; Lowry and Zehring, 2017). One of the most promising

interaction. Monalizumab, the first-in-class monoclonal antibody checkpoint inhibitor targeting

NKG2A, enhances anti-tumor immunity by activating cytotoxic activities of effector CD8+ T cells

and NK cells (Andre et al., 2018; Creelan and Antonia, 2019; van Hall et al., 2019). In our study,

co-complex structural analysis revealed steric clashes between a 3H4 Fab and the NK inhibitory

receptor NKG2A/CD94 when docked onto HLA-E-VL9, which explained the mechanism of 3H4

336 IgM enhancing NKG2A+ NK cell killing. Notably, 3H4 IgM enhanced the cytotoxicity of an

337 NKG2A + human NK cell line NK92, that is a safe and established cell line for adoptive

338 immunotherapy in phase I clinical trials (Klingemann et al., 2016). Therefore, 3H4 which targets

339 HLA-E-VL9 could have potential as an alternative to NKG2A targeting antibodies such as

340 Monalizumab as a check point inhibitor for immunotherapy. 
In summary, our study has demonstrated a novel specificity of IgM natural antibodies, that of recognition of HLA-E-VL9 peptide complexes, which suggests a NK cell immunoregulatory

343 role. The isolation of antibody $3 \mathrm{H} 4$ suggested that mouse could be a repository for this and

344 other anti-HLA-E-peptide antibodies that warrant further development as therapeutic agents.

345 Finally, the methods used here provide a means to rapidly isolate mAbs to other HLA/peptide

346 complexes such as HLA-E-SIV/HIV peptides (Hansen et al., 2016; Walters et al., 2018),

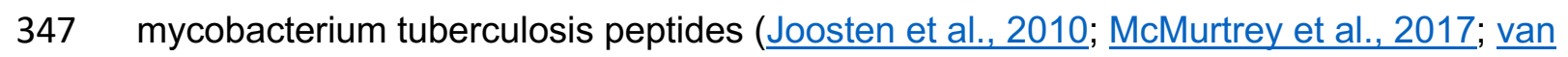

348 Meijgaarden et al., 2015), or HLA class I-presented neoantigen peptides that are derived from 349 mutated tumor tissues (Chen et al., 2019; Garcia-Garijo et al., 2019).

MATERIALS AND METHODS

Cell Lines

K562-E cells (K562 cells stably expressing HLA-E) and K562-E/UL49.5 cells (with a TAPinhibitor UL49.5) are kindly provided by Dr. Thorbald van Hall from Leiden University (Lampen et al., 2013). All the other cells used in this study are from ATCC. 293T cells (ATCC CRL-3216) were maintained in Dulbecco's Modified Eagle's Medium (DMEM; Gibco, Catalog\# 10564) supplemented with $10 \%$ fetal bovine serum (FBS; Gibco, Catalog\# 10099141) and 1\% penicillin/streptomycin (Gibco, Catalog\# 10378016). K562 cells (ATCC CCL-243), K562-E cells and K562-E/UL49.5 cells were cultured in Iscove's Modified Dulbecco's Medium (IMDM; Hyclone, Catalog\# SH30228.01) supplemented with 10\% FBS. Jurkat, DU-4475 and U-937 cells were cultured in RPMI-1640 medium (Gibco, Catalog\# 72400) supplemented with 10\% FBS.

363 SiHa cells were cultured in Minimum Essential Medium (MEM; Gibco, Catalog\# 11095080)

364 supplemented with 10\% FBS. The NK-92 human cell line (ATCC CRL-2407) was cultured in 365 Alpha Minimum Essential medium ( $\alpha-M E M ;$ Gibco, Catalog\# 12561072) supplemented with $3662 \mathrm{mM}$ L-glutamine, $0.2 \mathrm{mM}$ inositol, $0.1 \mathrm{mM}$ 2-mercaptoethanol, $0.02 \mathrm{mM}$ folic acid, $100 \mathrm{U} / \mathrm{ml}$ 
recombinant IL-2 (Biolegend, Catalog\# 589108), 12.5\% horse serum (Gibco, Catalog\# 16050122 ) and $12.5 \%$ FBS. All the cells were maintained at $37^{\circ} \mathrm{C}, 5 \% \mathrm{CO} 2$ in humidified incubators.

\section{Animals}

Transgenic mice carrying human $\beta 2$-microglobulin $(\beta 2 m)$ and HLA-B*27:05 genes were obtained from Jackson lab (B6.Cg-Tg(B2M,HLA-B²7:05)56-3Trg/DcrJ; Stock\# 003428). Hemizygous mice were used in this experiment, as this strain is homozygous lethal. For

375 hemizygous mice genotyping, peripheral blood lymphocytes (PBLs) were isolated and stained using mouse CD45 antibody (Biolegend, Catalog\# 103122), human HLA class I antibody

377 (Biolegend, Catalog\# 311406) and human $\beta 2 \mathrm{~m}$ antibody (Biolegend, Catalog\# 316312). All animal experiments were conducted with approved protocols from the Duke University Institutional Animal Care and Use Committee.

\section{Human Subjects}

Human leukapheresis frozen vials were collected by the External Quality Assurance Program Oversight Laboratory (EQAPOL) (Sanchez et al., 2014a; Sanchez et al., 2014b). Samples from four male donors were used in this study. Table S5 shows the clinical characteristics of the individuals studied. All experiments that related to human subjects was carried out with the informed consent of trial participants and in compliance with Institutional

387 Review Board protocols approved by Duke University Medical Center.

\section{Peptide synthesis}

The VL9 peptide (VMAPRTVLL) was synthesized to >85\% purity via Fmoc (9-

391 fluorenylmethoxy carbonyl) chemistry by Genscript USA and reconstituted to 200mM in DMSO. 


\section{HLA-E-peptide protein refolding and purification}

$\beta 2$-microglobulin, previously purified from inclusion bodies in a Urea-MES buffer, was added to a refolding buffer to achieve a final concentration of $2 \mu \mathrm{M}$. The refold buffer comprised 100 $\mathrm{mM}$ Tris pH8.0, 400mM L-arginine monohydrochloride, 2mM EDTA, 5mM reduced glutathione

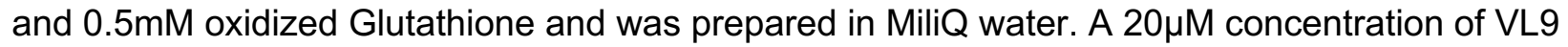
peptide (VMAPRTVLL), previously reconstituted to $200 \mathrm{mM}$ in DMSO, was added to the refolding buffer followed by HLA-E*0103 heavy chain, which was pulsed into the refold to a final concentration of $1 \mu \mathrm{M}$. Once the refold had incubated for $72 \mathrm{hrs}$ at $4{ }^{\circ} \mathrm{C}$ it was filtered through a 1.0 $\mathrm{mm}$ cellular nitrate membrane and concentrated in the VivaFlow 50R and VivaSpin Turbo Ultrafiltration centrifugal systems with $10 \mathrm{kDa}$ molecular weight cut-offs. The concentrated samples were injected onto a Superdex S75 16/60 column and refolded protein eluted according to size into phosphate buffered saline (PBS). Eluted protein complexes were validated by non-reducing SDS-PAGE electrophoresis on NuPAGE $12 \%$ Bis-Tris protein gels and further concentrated via VivaSpin Turbo Ultrafiltration centrifugal device to $1.1 \mathrm{mg} / \mathrm{mL}$.

HLA-E-peptide biotinylation and tetramer generation

HLA-E-peptide samples requiring biotinylation were subsequently buffered exchanged on Sephadex G-25 PD10 columns (GE Healthcare, UK) into 10mM Tris buffer using commercially available BirA enzyme (Avidity, USA) following the manufacturer's instructions. Following overnight biotinylation, protein samples were subsequently purified into $20 \mathrm{mM}$ Tris $\mathrm{pH} 8,100 \mathrm{mM}$

$413 \mathrm{NaCl}$ buffer or PBS on a HiLoad 16/600 Superdex 75pg column using an AKTA size exclusion

414 fast protein liquid chromatography (FPLC) system. Correctly folded $\beta 2 m-H L A-E^{*} 01: 03-$

415 peptide complexes were subsequently concentrated to $2 \mathrm{mg} / \mathrm{mL}$ and snap frozen.

$416 \quad$ HLA-E*01:03 tetramers were generated via conjugation to various fluorescent labels

417 including Extravidin-PE (Sigma), Streptavidin-bound APC (Biolegend, San Diego) or BV421

418 (Biolegend, San Diego) at a Molar ratio of 4:1 as previously described (Braud et al., 1998). 


\section{Immunization in HLA-B27/ß2m Transgenic Mice}

HLA-B27/ $\beta 2 m$ transgenic mice $(n=23)$ were intramuscularly (i.m.) immunized with pooled

HLA-E-RL9HIV complex (12.5 $\mu \mathrm{g} /$ animal) and HLA-E-RL9SIV complex (12.5 $\mu \mathrm{g} / \mathrm{animal})$

423 adjuvanted with STR8S-C at weeks $0,2,4,6,12$ and 16. MAb $3 \mathrm{H} 4$ was isolated from one of the

424 mice in this study. In another experiment, HLA-B27/ $\beta 2 \mathrm{~m}$ transgenic mice $(n=10)$ were i.p.

425 immunized with either HLA-E-RL9HIV SCT transfected 293T cells $\left(2 \times 10^{6}\right.$ cells/animal) or HLA-

426 E-RL9SIV SCT transfected 293 T cells $\left(2 \times 10^{6}\right.$ cells/animal) at weeks $0,2,4,6,17$ and 19. In the

427 third experiment, HLA-B27/ $32 \mathrm{~m}$ transgenic mice $(n=10)$ were i.m. immunized with HLA-E-VL9

428 complex (25 $\mu$ g/animal) adjuvanted with STR8S-C at Week 0, 2 and 4, following by

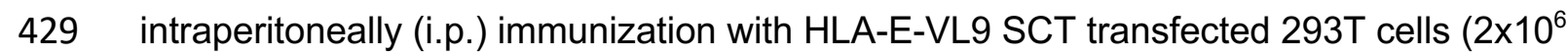

430 cells/animal) at Week 14, 16 and 18. Serum titers were monitored by ELISA Mice with high

431 binding antibody titers were selected for the subsequent spleen cell fusion and B cell sorting

432 experiments.

Hybridoma Cell Line Generation and Monoclonal Antibody Production

Mice were boosted with the indicated priming antigen 3 days prior to fusion. Spleen cells

were harvested and fused with NS0 murine myeloma cells using PEG1500 to generate

hybridomas. After 2 weeks, supernatant of hybridoma clones were collected and screened by

flow cytometry-based high throughput screening (HTS). Specifically, we tested for antibodies

439 differentially binding 293T cells transiently transfected with plasmid DNA expressing single

440 chain peptide-HLA-E-ß2m trimers so that they expressed HLA-E-RL9HIV, HLA-E-RL9SIV or

441 HLA-E-VL9 at the cell surface. Hybridomas cells that secreted HLA-E-VL9 antibodies were

442 cloned by limiting dilution for at least 5 rounds until the phenotypes of all limiting dilution wells

443 are identical. IgG mAbs were purified by protein $\mathrm{G}$ affinity chromatography, while IgM mAbs

444 were purified by ammonium sulfate precipitation and by Superose 6 column size-exclusion 
445 chromatography in AKTA Fast Protein Liquid Chromatography (FPLC) system. The VH and VL

446 sequences of mAbs were amplified from hybridoma cell RNA using primers reported previously

447 (Tian et al., 2016; von Boehmer et al., 2016).

\section{Cell Surface Staining and High-Throughput Screening (HTS)}

HLA-E SCT constructs encoding HLA-E-VL9, HLA-E-RL9HIV, or HLA-E-RL9SIV were

451 transfected into 293T cells using GeneJuice transfection reagent (Novagen, Catalog\# 70967).

452 For epitope mapping experiment, a panel of HLA-E-VL9 SCT constructs with single amino acid

453 mutations were transfected into 293T cells using the same method. Cells were dissociated with

$454 \quad 0.1 \%$ EDTA at 48 hours post-transfection and stained with a Fixable Near-IR Dead Cell Stain Kit

455 (Thermo Fisher, Catalog\# L34976). After washing, primary antibodies (supernatant from

456 hybridoma cells, supernatant from transfected cells, or purified antibodies) were added and

457 incubated with cells for 1 hour at $4^{\circ} \mathrm{C}$, following by staining with 1:1000 diluted secondary

458 antibodies for 30 mins at $4^{\circ} \mathrm{C}$. For mouse primary antibodies, we used Alexa Fluor 555 (AF555)

459 conjugated goat anti-mouse IgG $(\mathrm{H}+\mathrm{L})$ (Thermo Fisher, Catalog\# A32727) or Alexa Fluor 647

460 (AF647) conjugated goat anti-mouse $\lg \mathrm{G}(\mathrm{H}+\mathrm{L})$ (Thermo Fisher, Catalog\# A32728) as

461 secondary antibodies; for human primary antibodies, we used AF555 conjugated goat anti-

462 human IgG $(\mathrm{H}+\mathrm{L})$ (Thermo Fisher, Catalog\# A-21433) or AF647 conjugated goat anti-human

$463 \lg (\mathrm{H}+\mathrm{L})$ (Thermo Fisher, Catalog\# A-21445) as secondary antibodies. Cells were then

464 washed 3 times and resuspended in fixation buffer (1\% formaldehyde in PBS, pH7.4). Data

465 were acquired on a BD LSR II flow cytometer and analyzed using FlowJo version 10.

467 3H4 Fab production

468 A humanized version of the $3 \mathrm{H} 4$ antibody (3H4-hulgG1) was digested to produce Fab

469 fragments using the Pierce Fab Preparation kit (ThermoFisher SCIENTIFIC). 3H4 Fab-retrieved 470 sample was further purified by size exclusion on a Superdex S75 16/60 column and eluted into 
471 PBS buffer. Following concentration to $1.1 \mathrm{mg} / \mathrm{mL}$ and SDS-PAGE gel-based validation, $3 \mathrm{H} 4$

472 Fab purified material was incubated for 1 hours on ice with freshly purified HLA-E-VL9. The

473 combined 3H4:Fab-HLA-E-VL9 sample was concentrated to $7.5 \mathrm{mg} / \mathrm{mL}$ prior to crystallographic

474 set-up.

475

476 Crystallization screening

477 Crystals were grown via sitting drop vapour-diffusion at $20^{\circ} \mathrm{C}$ in a $200 \mathrm{~nL}$ drop with a $1: 1$

478 protein to reservoir ratio (Walter et al., 2005). The 3H4 Fab-HLA-E(VL9) co-complex crystallized

479 in $20 \%$ PEG 8000, 0.1 M Na HEPES at pH 7, in the ProPlex sparse matrix screen. Crystals

480 were cryo-preserved in $25 \%$ glycerol and diffraction data were collected at the 103 beamline of

481 Diamond Light Source.

482

Crystallographic analysis

Diffraction data were merged and indexed in xia2 dials (Winter et al., 2018). Outer shell reflections were excluded from further analysis to ensure the $\mathrm{CC}_{1 / 2}$ value exceeded the minimum threshold (>0.5) in each shell (Karplus and Diederichs, 2012). Sequential molecular replacement was carried out in MolRep of the CCP4i suite using molecule one of the previously published Mtb44-bound HLA-E structure with the peptide coordinates deleted (PDB ID: 6GH4) and one molecule of the previously published anti-APP-tag Fab structure (PDB ID: 6HGU) as phasing models (Vagin and Teplyakov, 2010; Winn et al., 2011). Rigid body and retrained

491 refinement were subsequently carried out by Phenix.refine (Afonine et al., 2012) in between

492 manual model building in Coot (Emsley et al., 2010). Model geometry was validated by

493 MolProbity (Chen et al., 2010) and structural interpretation was conducted using the PyMOL

494 Molecular Graphics System, version 2.0 (Schrödinger, LLC) in addition to the PDBePISA

495 (Krissinel and Henrick, 2007) and PDBeFOLD (Krissinel and Henrick, 2004) servers. 


\section{Antigen-Specific Single B Cell Sorting}

HLA-E-VL9-specific human B cells were sorted in flow cytometry using a three-color sorting technique. Briefly, the stabilized HLA-E-ß2M-peptide complexes were made as tetramers and conjugated with different fluorophores. Human pan-B cells, including naïve and memory B cells, were isolated from PBMCs of healthy donors using human pan-B cell enrichment kit (STEMCELL, Catalog\# 19554). The isolated pan-B cells were then stained with IgM PerCpCy5.5 (Clone\# G20-127, BD Biosciences, Catalog\# 561285), IgD FITC (Clone\# IA6-2, BD Biosciences, Catalog\# 555778), CD3 PE-Cy5 (Clone\# HIT3a, BD Biosciences, Catalog\# 555341), CD235a PE-Cy5 (Clone\# GA-R2, BD Biosciences, Catalog\# 559944), CD10 PECF594 (Clone\# HI10A, BD Biosciences, Catalog\# 562396), CD27 PE-Cy7 (Clone\# O323, eBioscience, Catalog\# 25-0279), CD16 BV570 (Clone\# 3G8, Biolegend, Catalog\# 302035), CD14 BV605 (Clone\# M5E2, Biolegend, Catalog\# 301834), CD38 APC-AF700 (Clone\# LS198-

4-2, Beckman Coulter, Catalog\# B23489), CD19 APC-Cy7 (Clone\# LJ25C1, BD Biosciences, APC-conjugated HLA-E-RL9HIV tetramer). The cells were then stained with a Fixable Aqua

513 Dead Cell Stain Kit (Invitrogen, Catalog\# L34957). HLA-E-VL9-specific B cells were sorted in

514 BD FACSAria II flow cytometer (BD Biosciences) for viable CD3 ${ }^{\text {neg }} /$ CD14 ${ }^{\text {neg }} / C D 16^{\text {neg }}$ /CD235a ${ }^{\text {neg/CD19 }}$ pos / HLA-E-VL9 double-pos/ HLA-E-RL9HIV ${ }^{\text {neg/HLA-E-RL9SIV }}{ }^{\text {neg }}$ subset as single 516 cells in 96-well plates.

\section{PCR Amplification of Human Antibody Genes}

The $V_{H} D_{H} J_{H}$ and $V_{L} J_{L}$ genes were amplified by RT-PCR from the flow cytometry-sorted 520 single B cells using the methods as described previously (Liao et al., 2009; Wrammert et al.,

5212008 ) with modification. Primer details were listed in Tables S2. The PCR-amplified genes were 522 then purified and sequenced with $10 \mu \mathrm{M}$ forward and reverse primers. Sequences were 
523 analyzed by using the human library in Clonalyst for the VDJ arrangements of the

524 immunoglobulin IGHV, IGKV, and IGLV sequences and mutation frequencies (Kepler et al.,

525 2014). Clonal relatedness of $V_{H} D_{H} J_{H}$ and $V_{L} J_{L}$ sequences was determined as previously

526 described (Liao et al., 2013).

527

528 Expression of $V_{H} D_{H} J_{H}$ and $V_{L} J_{L}$ as Full-Length IgG Recombinant mAbs

529 Transient transfection of recombinant mAbs was performed as previously described (Liao et

530 al., 2009). Briefly, purified PCR products were used for overlapping PCR to generate linear

531 human antibody expression cassettes. The expression cassettes were transfected into $293 \mathrm{i}$

532 cells using ExpiFectamine (Thermo Fisher Scientific, Catalog\# A14525). The supernatant

533 samples containing recombinant antibodies were used for cell surface staining and HTS assay

534 to measure the binding reactivities.

535 The selected human antibody genes were then synthesized and cloned (GenScript) in a

536 human IgG1 backbone with 4A mutations to enhance antibody-dependent cell-mediated

537 cytotoxicity (ADCC) or a human lgG2 $\sigma$ backbone with mutations that abolish ADCC (Saunders,

538 2019). Recombinant IgG mAbs were then produced in HEK293i suspension cells by transfection

539 with ExpiFectamine and purified using Protein A resin. The purified mAbs were run in SDS-

540 PAGE for Coomassie blue staining and western blot. Antibodies with aggregation were further

541 purified in AKTA FPLC system using a Superdex 200 size-exclusion column.

\section{Surface Plasmon Resonance (SPR)}

$544 \quad$ Surface plasmon resonance assays were performed on a BIAcore 3000 instrument, and

545 data analysis was performed with BIAevaluation 3.0 software as previously described (Liao et

546 al., 2006). Briefly, streptavidin was directly immobilized to CM5 sensor chips, then biotinylated

547 HLA-E-peptide complexes (HLA-E-VL9, HLA-E-RL9SIV, HLA-E-RL9HIV and mock control)

548 were bound to the immobilized streptavidin. Purified mAbs flowed over CM5 sensor chips at 
concentrations of $100 \mu \mathrm{g} / \mathrm{ml}$, and antibody binding was monitored in real-time at $25^{\circ} \mathrm{C}$ with a continuous flow of PBS at $30 \mu \mathrm{l} / \mathrm{min}$.

\section{ELISA}

Direct binding ELISAs were conducted in 384-well ELISA plates coated with $2 \mu \mathrm{g} / \mathrm{ml}$ of Ctrap-stabilized HLA-E-VL9, C-trap-stabilized HLA-E-RL9HIV or C-trap-stabilized HLA-E-RL9SIV in $0.1 \mathrm{M}$ sodium bicarbonate overnight at $4^{\circ} \mathrm{C}$. Plates were washed with PBS $+0.05 \%$ Tween 20

556 and blocked with 3\% BSA in PBS at room temperature for $1 \mathrm{~h}$. MAb samples were incubated for

$5571 \mathrm{~h}$ in 3-fold serial dilutions starting at $100 \mu \mathrm{g} / \mathrm{ml}$, followed by washing with PBS-0.05\% Tween

20. HRP-conjugated goat anti-human IgG secondary Ab (SouthernBiotech, catalog\# 2040-05) was diluted to 1: 10,000 in 1\% BSA in PBS-0.05\% Tween 20 and incubated at room temperature for $1 \mathrm{~h}$. For sandwich ELISA, 384-well ELISA plates were coated with HLA-E-VL9 antibodies in a 3-fold dilution starting from $100 \mu \mathrm{g} / \mathrm{mL}$ in $0.1 \mathrm{M}$ sodium bicarbonate overnight at $4^{\circ} \mathrm{C}$. Plates were washed with PBS $+0.05 \%$ Tween 20 and blocked with $3 \%$ BSA in PBS at room temperature for $1 \mathrm{~h}$. C-trap-stabilized HLA-E-VL9, C-trap-stabilized HLA-E-RL9HIV, Ctrap-stabilized HLA-E-RL9SIV, or diluent control were then added at $2 \mu \mathrm{g} / \mathrm{mL}$ and incubated at room temperature for $1 \mathrm{~h}$. After washing, HRP-conjugated anti-human $\beta 2 \mathrm{M}$ antibody (Biolegend, catalog\# 280303) were added at $0.2 \mu \mathrm{g} / \mathrm{mL}$ and incubated at room temperature for $1 \mathrm{~h}$. These plates were washed for 4 times and developed with tetramethylbenzidine substrate (SureBlue Reserve). The reaction was stopped with $1 \mathrm{M} \mathrm{HCl}$, and optical density at $450 \mathrm{~nm}\left(\mathrm{OD}_{450}\right)$ was determined.

\section{Antibody Poly-Reactivity Assays}

572 All mAbs isolated from mice and human were tested for ELISA binding to nine autoantigens

573 - Sjogren's syndrome antigen A (SSA), Sjogren's syndrome antigen (SSB), Smith antigen (Sm), 574 ribonucleoprotein (RNP), scleroderma 70 (Scl-70), Jo-1 antigen, double-stranded DNA 
575 (dsDNA), centromere B (Cent B), and histone as previously described (Han et al., 2017; Liao et

576 al., 2011). Indirect immunofluorescence assay of mAbs binding to HEp-2 cells (Inverness

577 Medical Professional Diagnostics, Princeton, NJ) was performed as previously described

578 (haynes et al., 2005; Liao et al., 2011). MAbs 2F5 (Yang et al., 2013) and 17B (Moore and

579 Sodroski, 1996) were used as positive and negative controls, respectively. All antibodies were

580 screened in two independent experiments.

581

582 Negative Stain Electron Microscopy of IgM antibodies

$583 \quad$ FPLC purified IgM antibodies were diluted to $0.08 \mathrm{mg} / \mathrm{ml}$ in HEPES-buffered saline $(\mathrm{pH} 7.4)$

$584+5 \%$ glycerol, and stained with $2 \%$ uranyl formate. Images were obtained with a Philips EM420

585 electron microscope at 82,000 magnification and processed in Relion 3.0.

Microbiome-derived Peptide Prediction

VL9 peptide sequence was first searched by similarity in NCBI microbial protein BLAST.

589 The BLAST results were then analyzed for HLA-E binding epitope prediction using HLA class I

590 peptide binding algorithms NetMHC 4.0 (Andreatta and Nielsen, 2016; Nielsen et al., 2003).

591 Epitopes that have HLA-E binding prediction scores $>0.1$, length $=9$ aa, and are relative to 592 human microbiome were synthesized for validation experiments.

\section{Peptide-Pulsing in K562-E Cells}

K562-E cells and K562-E/UL49.5 cells were resuspended with fresh IMDM media with 10\%

$597 \mu \mathrm{M}$. The cell/peptide mixtures were incubated at $26^{\circ} \mathrm{C}$ with $5 \% \mathrm{CO}_{2}$ for $20-22$ hours and were

598 transferred to $37^{\circ} \mathrm{C}$ for 2 hours with $5 \% \mathrm{CO}_{2}$ before use. In the following $\mathrm{mAb}$ staining

599 experiment, medium with $100 \mu \mathrm{M}$ peptides was used to maintain peptide concentration. 


\section{NK Cell Cytotoxicity Assay}

NK Cell Cytotoxicity was measured by ${ }^{51} \mathrm{Cr}$ release assay. Human NK-92 cells were used as effector cells in our study. Transfected 293T cells were used as target cells. Target cells were counted, washed, resuspended in R10 at $1 \times 10^{7}$ cell/ml, and labeled with $\mathrm{Na}_{2}{ }^{51} \mathrm{CrO}_{4}$ at 250

$605 \mu \mathrm{Ci} / \mathrm{ml}$ for 2 hours at $37^{\circ} \mathrm{C}$. After washing three times using R10, cells were mixed with effector 606 cells in a final effector to target (E:T) ratio of 60:1 and 6:1 in triplicate wells in a flexible 96 well 607 round bottom plates (PerkinElmer, Catalog\# 1450-401). The plates were inserted in flexible 96608 well plate cassettes (PerkinEImer, Catalog\# 1450-101), sealed and incubated at $37^{\circ} \mathrm{C}$ for 4

609 hours. After the incubation, cells were pelleted by centrifugation, and from the top of the well, 610 add 25 ul of supernatant to a rigid 96 well isoplates (PerkinElmer, Catalog\#1450-514) containing 611150 ul of Ultima Gold LSC Cocktail (Sigma, Catalog\# L8286). The plates were inserted in rigid 612 96-well plate cassettes (PerkinElmer, Catalog\# 1450-105), sealed and counted on Perkin Elmer

613 Microbeta Triux 1450 counter. ${ }^{51} \mathrm{Cr}$ labeled target cells without effector cells were set as a 614 spontaneous release control, and ${ }^{51} \mathrm{Cr}$ labeled target cells mixed with detergent (2\% Triton X615 100) were used as a maximum release control. The percentages of specific lysis were 616 calculated with the formulation: The Percentages of Specific Lysis $\left({ }^{51} \mathrm{Cr}\right.$ Release \%) $=$ 617 [(Experimental Release - Spontaneous Release)/ (Maximum Release - Spontaneous Release)] $618 \times 100$.

\section{Statistics Analysis}

Data were plotted using Prism GraphPad 8.0 or visualized using the ComplexHeatmap R

622 package. Significant analysis was performed using two-tailed Mann-Whitney tests or chi-square 623 test of independence to compare differences between groups with $p$-value $<0.05$ considered 624 significant. 


\section{7}

628

629

630

631

632

633

634

635

636

637

638

639

640

641

642

643

644

645

646

647

648

649

650

651

\section{ACKNOWLEDGMENTS}

We thank Dr. Thorbald van Hall from Leiden University for kindly providing the K562-E cells and K562-E/UL49.5 cells. We thank Duke Human Vaccine Institute (DHVI) programs and finance staff for project oversight and the contributions of technical staff at the DHVI, including Jordan Cocchiaro, Kelly Soderberg, Ahmed Yousef Abuahmad, Yunfei Wang, Giovanna Hernandez, Esther Lee, Paige Power, Aja Sanzone, Brenna Harrington, Andrew Foulger, Amanda Newman, Cindy Bowman, Grace Stevens, Laura Sutherland, Margaret Deyton, Victoria Gee-Lai, Tarra Von Holle, Thad Gurley, Madison Berry, Kara Anasti, Katayoun Mansouri, Erika Dunford, and Dawn Jones Marshall. We thank the DHVI Flow Cytometry Core for technical assistance. This study was funded by the Collaboratory of AIDS Researchers for Eradication (CARE; UM1AI126619), the Center for HIVIAIDS Vaccine Immunology-Immunogen Discovery (CHAVI-ID; UMI-AI100645) grant and the Consortium for HIVIAIDS Vaccine Development grant (CHAVD; UM1AI144371) from NIH/NIAID/DAIDS, and the Bill and Melinda Gates Foundation OPP1108533.

\section{AUTHOR CONTRIBUTIONS}

D.L. immunized the mice, generated the hybridomas, sorted B cells, cloned the antibodies and analyzed data. S.B. made single-chain trimer constructs, performed epitope mapping experiments and analyzed data. G.G, L.W. and M.Q. prepared the antigens and HLA-E tetramers. L.W., G.G., D.R. and K.H performed structural experiments with oversight from E.Y.J.. D.W.C. helped with flow cytometry sorting set-up. R.S., R.P. and M.B. performed hybridoma experiments, ELISA assays and help with ${ }^{51} \mathrm{Cr}$ release assays. R.J.E. oversaw negative stain EM. M.A. supervised and interpreted the SPR experiments. K.W. oversaw and performed antibody gene sequence analysis. Z.M. and M.B. helped with antibody isolation. K.O.S. oversaw antigen production. P.B. provided advice on NK cell assays and contributed to 
652

653

654

655

656

657

658

659

660

661

662

663

664

665

666

667

668

669

670

671

672

673

674

675

676

677

678

679

680

study design and data interpretation. B.F.H., G.G. D.L. and A.J.M. conceived, designed, coordinated the study. D.L. and B.F.H. wrote the manuscript which was reviewed by all authors.

\section{DECLARATION OF INTERESTS}

D.L., S.B., G.G., A.J.M. and B.F.H. have patents submitted on select aspects of the material in this paper.

\section{REFERENCES}

Afonine, P.V., Grosse-Kunstleve, R.W., Echols, N., Headd, J.J., Moriarty, N.W., Mustyakimov, M., Terwilliger, T.C., Urzhumtsev, A., Zwart, P.H., and Adams, P.D. (2012). Towards automated crystallographic structure refinement with phenix.refine. Acta Crystallogr D Biol Crystallogr 68, 352-367.

Alberu, J., Morales-Buenrostro, L.E., de Leo, C., Vargas-Rojas, M.I., Marino-Vazquez, L.A., and Crispin, J.C. (2007). A non-allogeneic stimulus triggers the production of de novo HLA antibodies in healthy adults. Transpl Immunol 18, 166-171.

Aldrich, C.J., DeCloux, A., Woods, A.S., Cotter, R.J., Soloski, M.J., and Forman, J. (1994). Identification of a Tap-dependent leader peptide recognized by alloreactive $T$ cells specific for a class Ib antigen. Cell 79, 649-658.

Andre, P., Brunet, C., Guia, S., Gallais, H., Sampol, J., Vivier, E., and Dignat-George, F. (1999). Differential regulation of killer cell Ig-like receptors and CD94 lectin-like dimers on NK and T lymphocytes from HIV-1-infected individuals. Eur J Immunol 29, 1076-1085.

Andre, P., Denis, C., Soulas, C., Bourbon-Caillet, C., Lopez, J., Arnoux, T., Blery, M., Bonnafous, C., Gauthier, L., Morel, A., et al. (2018). Anti-NKG2A mAb Is a Checkpoint Inhibitor that Promotes Anti-tumor Immunity by Unleashing Both T and NK Cells. Cell 175, 1731-1743 e1713.

Andreatta, M., and Nielsen, M. (2016). Gapped sequence alignment using artificial neural networks: application to the MHC class I system. Bioinformatics 32, 511-517.

Braud, V., Jones, E.Y., and McMichael, A. (1997). The human major histocompatibility complex class Ib molecule HLA-E binds signal sequence-derived peptides with primary anchor residues at positions 2 and 9. Eur J Immunol 27, 1164-1169. 
681 Braud, V.M., Allan, D.S., O'Callaghan, C.A., Soderstrom, K., D'Andrea, A., Ogg, G.S., Lazetic, S., 682 Young, N.T., Bell, J.I., Phillips, J.H., et al. (1998). HLA-E binds to natural killer cell receptors 683 CD94/NKG2A, B and C. Nature 391, 795-799.

684 Brooks, A.G., Posch, P.E., Scorzelli, C.J., Borrego, F., and Coligan, J.E. (1997). NKG2A 685 complexed with CD94 defines a novel inhibitory natural killer cell receptor. J Exp Med 185, 795686800.

687 Chen, F., Zou, Z., Du, J., Su, S., Shao, J., Meng, F., Yang, J., Xu, Q., Ding, N., Yang, Y., et al. 688 (2019). Neoantigen identification strategies enable personalized immunotherapy in refractory 689 solid tumors. J Clin Invest 129, 2056-2070.

690 Chen, H., Zhang, Y., Ye, A.Y., Du, Z., Xu, M., Lee, C.S., Hwang, J.K., Kyritsis, N., Ba, Z., Neuberg, 691 D., et al. (2020). BCR selection and affinity maturation in Peyer's patch germinal centres. Nature $692582,421-425$.

693 Chen, V.B., Arendall, W.B., 3rd, Headd, J.J., Keedy, D.A., Immormino, R.M., Kapral, G.J., Murray, 694 L.W., Richardson, J.S., and Richardson, D.C. (2010). MolProbity: all-atom structure validation for 695 macromolecular crystallography. Acta Crystallogr D Biol Crystallogr 66, 12-21.

696 Chiossone, L., Dumas, P.Y., Vienne, M., and Vivier, E. (2018). Natural killer cells and other innate 697 lymphoid cells in cancer. Nat Rev Immunol 18, 671-688.

698 Colonna, M., and Samaridis, J. (1995). Cloning of immunoglobulin-superfamily members 699 associated with HLA-C and HLA-B recognition by human natural killer cells. Science 268, 405700408.

701 Creelan, B.C., and Antonia, S.J. (2019). The NKG2A immune checkpoint - a new direction in 702 cancer immunotherapy. Nat Rev Clin Oncol 16, 277-278.

703 DeKosky, B.J., Kojima, T., Rodin, A., Charab, W., Ippolito, G.C., Ellington, A.D., and Georgiou, 704 G. (2015). In-depth determination and analysis of the human paired heavy- and light-chain 705 antibody repertoire. Nat Med 21, 86-91.

706 DeKosky, B.J., Lungu, O.I., Park, D., Johnson, E.L., Charab, W., Chrysostomou, C., Kuroda, D., 707 Ellington, A.D., Ippolito, G.C., Gray, J.J., et al. (2016). Large-scale sequence and structural 708 comparisons of human naive and antigen-experienced antibody repertoires. Proc Natl Acad Sci 709 U S A 113, E2636-2645.

710 Emsley, P., Lohkamp, B., Scott, W.G., and Cowtan, K. (2010). Features and development of Coot. 711 Acta Crystallogr D Biol Crystallogr 66, 486-501.

712 Garcia-Garijo, A., Fajardo, C.A., and Gros, A. (2019). Determinants for Neoantigen Identification.

713 Front Immunol 10, 1392. 
714 Giltiay, N.V., Giordano, D., and Clark, E.A. (2019). The Plasticity of Newly Formed B Cells. J

715 Immunol 203, 3095-3104.

716 Guillerey, C., Huntington, N.D., and Smyth, M.J. (2016). Targeting natural killer cells in cancer

717 immunotherapy. Nat Immunol 17, 1025-1036.

718 Han, Q., Williams, W.B., Saunders, K.O., Seaton, K.E., Wiehe, K.J., Vandergrift, N., Von Holle,

719 T.A., Trama, A.M., Parks, R.J., Luo, K., et al. (2017). HIV DNA-Adenovirus Multiclade Envelope

720 Vaccine Induces gp41 Antibody Immunodominance in Rhesus Macaques. J Virol 91.

721 Hansen, S.G., Wu, H.L., Burwitz, B.J., Hughes, C.M., Hammond, K.B., Ventura, A.B., Reed, J.S.,

722 Gilbride, R.M., Ainslie, E., Morrow, D.W., et al. (2016). Broadly targeted CD8(+) T cell responses

723 restricted by major histocompatibility complex E. Science 351, 714-720.

724 Haynes, B.F., Fleming, J., St Clair, E.W., Katinger, H., Stiegler, G., Kunert, R., Robinson, J.,

725 Scearce, R.M., Plonk, K., Staats, H.F., et al. (2005). Cardiolipin polyspecific autoreactivity in two

726 broadly neutralizing HIV-1 antibodies. Science 308, 1906-1908.

727 Hickey, M.J., Valenzuela, N.M., and Reed, E.F. (2016). Alloantibody Generation and Effector

728 Function Following Sensitization to Human Leukocyte Antigen. Front Immunol 7, 30.

729 Holodick, N.E., Rodriguez-Zhurbenko, N., and Hernandez, A.M. (2017). Defining Natural

730 Antibodies. Front Immunol 8, 872.

731 Hu, W., Wang, G., Huang, D., Sui, M., and Xu, Y. (2019). Cancer Immunotherapy Based on

732 Natural Killer Cells: Current Progress and New Opportunities. Front Immunol 10, 1205.

733 Joosten, S.A., van Meijgaarden, K.E., van Weeren, P.C., Kazi, F., Geluk, A., Savage, N.D.,

734 Drijfhout, J.W., Flower, D.R., Hanekom, W.A., Klein, M.R., et al. (2010). Mycobacterium

735 tuberculosis peptides presented by HLA-E molecules are targets for human CD8 T-cells with

736 cytotoxic as well as regulatory activity. PLoS Pathog 6, e1000782.

737 Kaiser, B.K., Pizarro, J.C., Kerns, J., and Strong, R.K. (2008). Structural basis for NKG2A/CD94

738 recognition of HLA-E. Proc Natl Acad Sci U S A 105, 6696-6701.

739 Karlhofer, F.M., Ribaudo, R.K., and Yokoyama, W.M. (1992). MHC class I alloantigen specificity

740 of Ly-49+ IL-2-activated natural killer cells. Nature 358, 66-70.

741 Karplus, P.A., and Diederichs, K. (2012). Linking crystallographic model and data quality. Science $742336,1030-1033$.

743 Kepler, T.B., Munshaw, S., Wiehe, K., Zhang, R., Yu, J.S., Woods, C.W., Denny, T.N., Tomaras,

744 G.D., Alam, S.M., Moody, M.A., et al. (2014). Reconstructing a B-Cell Clonal Lineage. II. Mutation,

745 Selection, and Affinity Maturation. Front Immunol 5, 170.

746 Kim, N., Lee, H.H., Lee, H.J., Choi, W.S., Lee, J., and Kim, H.S. (2019). Natural killer cells as a

747 promising therapeutic target for cancer immunotherapy. Arch Pharm Res 42, 591-606. 
Klingemann, H., Boissel, L., and Toneguzzo, F. (2016). Natural Killer Cells for Immunotherapy Advantages of the NK-92 Cell Line over Blood NK Cells. Front Immunol 7, 91.

750 Kraemer, T., Blasczyk, R., and Bade-Doeding, C. (2014). HLA-E: a novel player for 751 histocompatibility. J Immunol Res 2014, 352160.

752 Kraemer, T., Celik, A.A., Huyton, T., Kunze-Schumacher, H., Blasczyk, R., and Bade-Doding, C.

753 (2015). HLA-E: Presentation of a Broader Peptide Repertoire Impacts the Cellular Immune

754 Response-Implications on HSCT Outcome. Stem Cells Int 2015, 346714.

755 Krissinel, E., and Henrick, K. (2004). Secondary-structure matching (SSM), a new tool for fast

756 protein structure alignment in three dimensions. Acta Crystallogr D Biol Crystallogr 60, 2256-2268.

757 Krissinel, E., and Henrick, K. (2007). Inference of macromolecular assemblies from crystalline 758 state. J Mol Biol 372, 774-797.

759 Lampen, M.H., Hassan, C., Sluijter, M., Geluk, A., Dijkman, K., Tjon, J.M., de Ru, A.H., van der 760 Burg, S.H., van Veelen, P.A., and van Hall, T. (2013). Alternative peptide repertoire of HLA-E 761 reveals a binding motif that is strikingly similar to HLA-A2. Mol Immunol 53, 126-131.

762 Lee, N., Goodlett, D.R., Ishitani, A., Marquardt, H., and Geraghty, D.E. (1998a). HLA-E surface 763 expression depends on binding of TAP-dependent peptides derived from certain HLA class I 764 signal sequences. J Immunol 160, 4951-4960.

765 Lee, N., Llano, M., Carretero, M., Ishitani, A., Navarro, F., Lopez-Botet, M., and Geraghty, D.E. 766 (1998b). HLA-E is a major ligand for the natural killer inhibitory receptor CD94/NKG2A. Proc Natl 767 Acad Sci U S A 95, 5199-5204.

768 Liao, H.X., Chen, X., Munshaw, S., Zhang, R., Marshall, D.J., Vandergrift, N., Whitesides, J.F., 769 Lu, X., Yu, J.S., Hwang, K.K., et al. (2011). Initial antibodies binding to HIV-1 gp41 in acutely 770 infected subjects are polyreactive and highly mutated. J Exp Med 208, 2237-2249.

771 Liao, H.X., Levesque, M.C., Nagel, A., Dixon, A., Zhang, R., Walter, E., Parks, R., Whitesides, J., 772 Marshall, D.J., Hwang, K.K., et al. (2009). High-throughput isolation of immunoglobulin genes 773 from single human B cells and expression as monoclonal antibodies. J Virol Methods 158, 171774179.

775 Liao, H.X., Lynch, R., Zhou, T., Gao, F., Alam, S.M., Boyd, S.D., Fire, A.Z., Roskin, K.M., 776 Schramm, C.A., Zhang, Z., et al. (2013). Co-evolution of a broadly neutralizing HIV-1 antibody 777 and founder virus. Nature 496, 469-476.

778 Liao, H.X., Sutherland, L.L., Xia, S.M., Brock, M.E., Scearce, R.M., Vanleeuwen, S., Alam, S.M., 779 McAdams, M., Weaver, E.A., Camacho, Z., et al. (2006). A group M consensus envelope 780 glycoprotein induces antibodies that neutralize subsets of subtype B and C HIV-1 primary viruses. 781 Virology 353, 268-282. 
782 Lin, S.Y., Hameed, A., Liu, Y.C., Hsu, Y.H., Lai, W.A., and Young, C.C. (2013). Pseudomonas

783 formosensis sp. nov., a gamma-proteobacteria isolated from food-waste compost in Taiwan. Int

784 J Syst Evol Microbiol 63, 3168-3174.

785 Ljunggren, H.G., and Karre, K. (1985). Host resistance directed selectively against H-2-deficient 786 lymphoma variants. Analysis of the mechanism. J Exp Med 162, 1745-1759.

787 Ljunggren, H.G., and Karre, K. (1990). In search of the 'missing self': MHC molecules and NK cell 788 recognition. Immunol Today 11, 237-244.

789 Llano, M., Lee, N., Navarro, F., Garcia, P., Albar, J.P., Geraghty, D.E., and Lopez-Botet, M. (1998).

790 HLA-E-bound peptides influence recognition by inhibitory and triggering CD94/NKG2 receptors:

791 preferential response to an HLA-G-derived nonamer. Eur J Immunol 28, 2854-2863.

792 Lowry, L.E., and Zehring, W.A. (2017). Potentiation of Natural Killer Cells for Cancer 793 Immunotherapy: A Review of Literature. Front Immunol 8, 1061.

794 Mahapatra, S., Mace, E.M., Minard, C.G., Forbes, L.R., Vargas-Hernandez, A., Duryea, T.K., 795 Makedonas, G., Banerjee, P.P., Shearer, W.T., and Orange, J.S. (2017). High-resolution 796 phenotyping identifies NK cell subsets that distinguish healthy children from adults. PLoS One 12, $797 \mathrm{e} 0181134$.

798 Marin, R., Ruiz-Cabello, F., Pedrinaci, S., Mendez, R., Jimenez, P., Geraghty, D.E., and Garrido, 799 F. (2003). Analysis of HLA-E expression in human tumors. Immunogenetics 54, 767-775.

800 McKenna, R.M., Takemoto, S.K., and Terasaki, P.I. (2000). Anti-HLA antibodies after solid organ 801 transplantation. Transplantation 69, 319-326.

802 McMurtrey, C., Harriff, M.J., Swarbrick, G.M., Duncan, A., Cansler, M., Null, M., Bardet, W., 803 Jackson, K.W., Lewinsohn, D.A., Hildebrand, W., et al. (2017). T cell recognition of 804 Mycobacterium tuberculosis peptides presented by HLA-E derived from infected human cells. 805 PLoS One 12, e0188288.

806 Michaelsson, J., Teixeira de Matos, C., Achour, A., Lanier, L.L., Karre, K., and Soderstrom, K. 807 (2002). A signal peptide derived from hsp60 binds HLA-E and interferes with CD94/NKG2A 808 recognition. J Exp Med 196, 1403-1414.

809 Moore, J.P., and Sodroski, J. (1996). Antibody cross-competition analysis of the human 810 immunodeficiency virus type 1 gp120 exterior envelope glycoprotein. J Virol 70, 1863-1872.

811 Morales-Buenrostro, L.E., Terasaki, P.I., Marino-Vazquez, L.A., Lee, J.H., El-Awar, N., and Alberu, 812 J. (2008). "Natural" human leukocyte antigen antibodies found in nonalloimmunized healthy males.

813 Transplantation 86, 1111-1115.

814 New, J.S., King, R.G., and Kearney, J.F. (2016). Manipulation of the glycan-specific natural 815 antibody repertoire for immunotherapy. Immunol Rev 270, 32-50. 
816 Nielsen, M., Lundegaard, C., Worning, P., Lauemoller, S.L., Lamberth, K., Buus, S., Brunak, S.,

817 and Lund, O. (2003). Reliable prediction of T-cell epitopes using neural networks with novel

818 sequence representations. Protein Sci 12, 1007-1017.

819 O'Callaghan, C.A., Tormo, J., Willcox, B.E., Braud, V.M., Jakobsen, B.K., Stuart, D.I., McMichael,

820 A.J., Bell, J.I., and Jones, E.Y. (1998). Structural features impose tight peptide binding specificity

821 in the nonclassical MHC molecule HLA-E. Mol Cell 1, 531-541.

822 Pende, D., Falco, M., Vitale, M., Cantoni, C., Vitale, C., Munari, E., Bertaina, A., Moretta, F., Del

823 Zotto, G., Pietra, G., et al. (2019). Killer Ig-Like Receptors (KIRs): Their Role in NK Cell Modulation

824 and Developments Leading to Their Clinical Exploitation. Front Immunol 10, 1179.

825 Petrie, E.J., Clements, C.S., Lin, J., Sullivan, L.C., Johnson, D., Huyton, T., Heroux, A., Hoare,

826 H.L., Beddoe, T., Reid, H.H., et al. (2008). CD94-NKG2A recognition of human leukocyte antigen

827 (HLA)-E bound to an HLA class I leader sequence. J Exp Med 205, 725-735.

828 Raulet, D.H. (2006). Missing self recognition and self tolerance of natural killer (NK) cells. Semin

829 Immunol 18, 145-150.

830 Ravindranath, M.H., Kaneku, H., El-Awar, N., Morales-Buenrostro, L.E., and Terasaki, P.I.

831 (2010a). Antibodies to HLA-E in nonalloimmunized males: pattern of HLA-la reactivity of anti-

832 HLA-E-positive sera. J Immunol 185, 1935-1948.

833 Ravindranath, M.H., Taniguchi, M., Chen, C.W., Ozawa, M., Kaneku, H., El-Awar, N., Cai, J., and 834 Terasaki, P.I. (2010b). HLA-E monoclonal antibodies recognize shared peptide sequences on 835 classical HLA class la: relevance to human natural HLA antibodies. Mol Immunol 47, 1121-1131. 836 Rolle, A., Meyer, M., Calderazzo, S., Jager, D., and Momburg, F. (2018). Distinct HLA-E Peptide 837 Complexes Modify Antibody-Driven Effector Functions of Adaptive NK Cells. Cell Rep 24, 19678381976 e1964.

839 Sanchez, A.M., DeMarco, C.T., Hora, B., Keinonen, S., Chen, Y., Brinkley, C., Stone, M., Tobler, 840 L., Keating, S., Schito, M., et al. (2014a). Development of a contemporary globally diverse HIV 841 viral panel by the EQAPOL program. J Immunol Methods 409, 117-130.

842 Sanchez, A.M., Rountree, W., Berrong, M., Garcia, A., Schuetz, A., Cox, J., Frahm, N., Manak, 843 M., Sarzotti-Kelsoe, M., D'Souza, M.P., et al. (2014b). The External Quality Assurance Oversight 844 Laboratory (EQAPOL) proficiency program for IFN-gamma enzyme-linked immunospot (IFN845 gamma ELISpot) assay. J Immunol Methods 409, 31-43.

846 Saunders, K.O. (2019). Conceptual Approaches to Modulating Antibody Effector Functions and 847 Circulation Half-Life. Front Immunol 10, 1296.

848 Sensi, M., Pietra, G., Molla, A., Nicolini, G., Vegetti, C., Bersani, I., Millo, E., Weiss, E., Moretta, 849 L., Mingari, M.C., et al. (2009). Peptides with dual binding specificity for HLA-A2 and HLA-E are 
850

851

852

853

854

855

856

857

858

859

860

861

862

863

864

865

866

867

868

869

870

871

872

873

874

875

876

877

878

879

880

881

882

encoded by alternatively spliced isoforms of the antioxidant enzyme peroxiredoxin 5. Int Immunol 21, 257-268.

Souza-Fonseca-Guimaraes, F., Cursons, J., and Huntington, N.D. (2019). The Emergence of Natural Killer Cells as a Major Target in Cancer Immunotherapy. Trends Immunol 40, 142-158.

Sullivan, L.C., Westall, G.P., Widjaja, J.M., Mifsud, N.A., Nguyen, T.H., Meehan, A.C., Kotsimbos, T.C., and Brooks, A.G. (2015). The Presence of HLA-E-Restricted, CMV-Specific CD8+ T Cells in the Blood of Lung Transplant Recipients Correlates with Chronic Allograft Rejection. PLoS One 10, e0135972.

Taurog, J., Hammer, R., Maika, S., Sams, K., El-Zaatari, F., Stimpson, S., and Schwab, J. (1990). HLA-B27 transgenic mice as potential models of human disease. In Transgenic mice and mutants in $\mathrm{MHC}$ research (Springer), pp. 268-275.

Tian, M., Cheng, C., Chen, X., Duan, H., Cheng, H.L., Dao, M., Sheng, Z., Kimble, M., Wang, L., Lin, S., et al. (2016). Induction of HIV Neutralizing Antibody Lineages in Mice with Diverse Precursor Repertoires. Cell 166, 1471-1484 e1418.

Tomasec, P., Braud, V.M., Rickards, C., Powell, M.B., McSharry, B.P., Gadola, S., Cerundolo, V., Borysiewicz, L.K., McMichael, A.J., and Wilkinson, G.W. (2000). Surface expression of HLA-E, an inhibitor of natural killer cells, enhanced by human cytomegalovirus gpUL40. Science 287 , 1031.

Vagin, A., and Teplyakov, A. (2010). Molecular replacement with MOLREP. Acta Crystallogr D Biol Crystallogr 66, 22-25.

van Hall, T., Andre, P., Horowitz, A., Ruan, D.F., Borst, L., Zerbib, R., Narni-Mancinelli, E., van der Burg, S.H., and Vivier, E. (2019). Monalizumab: inhibiting the novel immune checkpoint NKG2A. J Immunother Cancer 7, 263.

van Meijgaarden, K.E., Haks, M.C., Caccamo, N., Dieli, F., Ottenhoff, T.H., and Joosten, S.A. (2015). Human CD8+ T-cells recognizing peptides from Mycobacterium tuberculosis (Mtb) presented by HLA-E have an unorthodox Th2-like, multifunctional, Mtb inhibitory phenotype and represent a novel human T-cell subset. PLoS Pathog 11, e1004671.

van Montfoort, N., Borst, L., Korrer, M.J., Sluijter, M., Marijt, K.A., Santegoets, S.J., van Ham, V.J., Ehsan, I., Charoentong, P., Andre, P., et al. (2018). NKG2A Blockade Potentiates CD8 T Cell Immunity Induced by Cancer Vaccines. Cell 175, 1744-1755 e1715.

von Boehmer, L., Liu, C., Ackerman, S., Gitlin, A.D., Wang, Q., Gazumyan, A., and Nussenzweig, M.C. (2016). Sequencing and cloning of antigen-specific antibodies from mouse memory B cells. Nat Protoc 11, 1908-1923. 
883

884

885

886

887

888

889

890

891

892

893

894

895

896

897

898

899

900

901

902

903

904

905

906

907

908

909

910

911

Walter, T.S., Diprose, J.M., Mayo, C.J., Siebold, C., Pickford, M.G., Carter, L., Sutton, G.C., Berrow, N.S., Brown, J., Berry, I.M., et al. (2005). A procedure for setting up high-throughput nanolitre crystallization experiments. Crystallization workflow for initial screening, automated storage, imaging and optimization. Acta Crystallogr D Biol Crystallogr 61, 651-657.

Walters, L.C., Harlos, K., Brackenridge, S., Rozbesky, D., Barrett, J.R., Jain, V., Walter, T.S., O'Callaghan, C.A., Borrow, P., Toebes, M., et al. (2018). Pathogen-derived HLA-E bound epitopes reveal broad primary anchor pocket tolerability and conformationally malleable peptide binding. Nat Commun 9, 3137.

Walters, L.C., McMichael, A.J., and Gillespie, G.M. (2020). Detailed and atypical HLA-E peptide binding motifs revealed by a novel peptide exchange binding assay. Eur J Immunol.

Winn, M.D., Ballard, C.C., Cowtan, K.D., Dodson, E.J., Emsley, P., Evans, P.R., Keegan, R.M., Krissinel, E.B., Leslie, A.G., McCoy, A., et al. (2011). Overview of the CCP4 suite and current developments. Acta Crystallogr D Biol Crystallogr 67, 235-242.

Winter, G., Waterman, D.G., Parkhurst, J.M., Brewster, A.S., Gildea, R.J., Gerstel, M., FuentesMontero, L., Vollmar, M., Michels-Clark, T., Young, I.D., et al. (2018). DIALS: implementation and evaluation of a new integration package. Acta Crystallogr D Struct Biol 74, 85-97.

Wrammert, J., Smith, K., Miller, J., Langley, W.A., Kokko, K., Larsen, C., Zheng, N.Y., Mays, I., Garman, L., Helms, C., et al. (2008). Rapid cloning of high-affinity human monoclonal antibodies against influenza virus. Nature 453, 667-671.

Yang, G., Holl, T.M., Liu, Y., Li, Y., Lu, X., Nicely, N.I., Kepler, T.B., Alam, S.M., Liao, H.X., Cain, D.W., et al. (2013). Identification of autoantigens recognized by the $2 \mathrm{~F} 5$ and $4 \mathrm{E} 10$ broadly neutralizing HIV-1 antibodies. J Exp Med 210, 241-256.

Yokoyama, W.M., and Kim, S. (2006). How do natural killer cells find self to achieve tolerance? Immunity 24, 249-257.

Yu, Y.Y., Netuschil, N., Lybarger, L., Connolly, J.M., and Hansen, T.H. (2002). Cutting edge: single-chain trimers of $\mathrm{MHC}$ class I molecules form stable structures that potently stimulate antigen-specific T cells and B cells. J Immunol 168, 3145-3149. 
bioRxiv preprint doi: https://doi org/10.1101/2020.12 03 403014 this version posted December 3, 2020. The copyright holder for this preprint (which was not certified by peer review) is the author/funder, who has granted bioRxiv a license to display the preprint in perpetuity. It is made available under aCC-BY-NC-ND 4.0 International license.

\section{FIGURES}
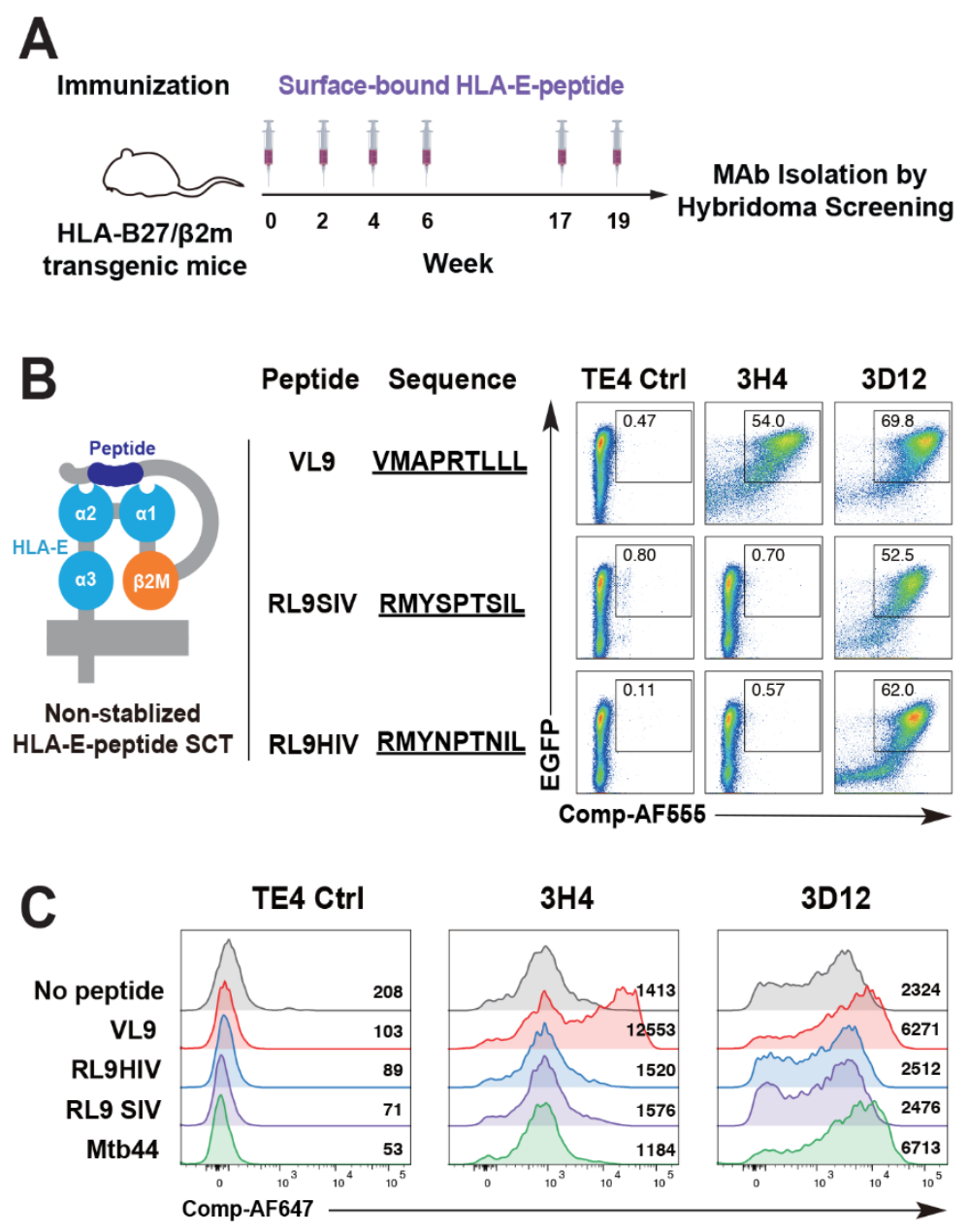

D

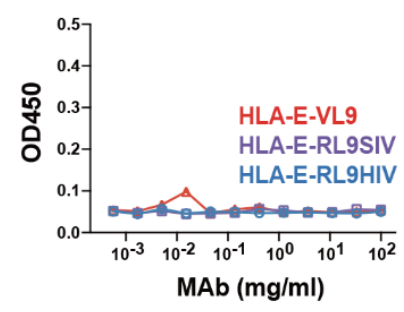

E

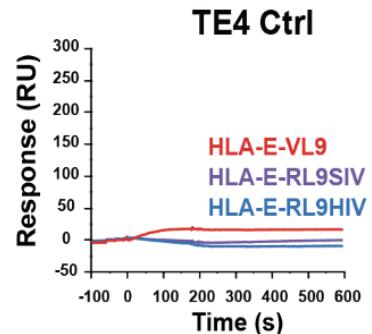

Time (s)
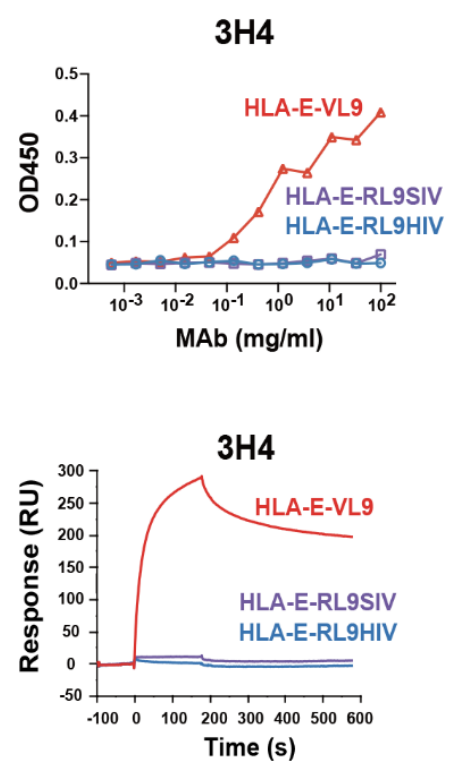
914 Figure 1. Isolation of monoclonal antibodies specifically targeting HLA-E-VL9 complex.

915 (A) HLA-E specific antibodies elicited by vaccination. HLA-B27/B2M transgenic (TG) mice

$916(n=10)$ were used to minimize the induction of antibodies to HLA class I and $\beta 2 \mathrm{M}$. Animals were

917 immunized with cell surface-expressing HLA-E-RL9 peptide (a peptide derived from HIV-1;

918 denoted RL9HIV hereafter) single-chain trimer (SCT)-transfected 293T cells (indicated by red

919 arrows).

920 (B) 3 H4 bound HLA-E-VL9 SCT-transfected 293T cells. All SCT constructs express EGFP to

921 indicate transfection efficiency. Transfected cells were stained with testing antibody and then an

922 Alexa fluor 555 (AF555)-anti-mouse $\lg (\mathrm{H}+\mathrm{L})$ secondary antibody. A control mouse $\lg M$ TE4 was

923 used as a negative control. Anti-pan-HLA-E antibody 3D12 was used as a positive control.

924 (C) 3 H4 bound VL9 peptide pulsed K562-HLA-E cells. RL9HIV, RL9SIV, Mtb44 peptides

925 served as peptide controls. TE4 and 3D12 were used as antibody controls. Peptide-pulsed cells

926 were stained with testing antibody and then an Alexa fluor 647 (AF647)-anti-mouse $\lg (\mathrm{H}+\mathrm{L})$

927 secondary antibody. Mean fluorescence intensity (MFI) of each sample is shown.

928 (D-E) 3H4 specifically bound to soluble HLA-E-VL9 complexes as measured by ELISA

929 and SPR. (D) ELISA plates were coated with $3 \mathrm{H} 4$ or control IgM TE4 in serial dilution, blocked,

930 and incubated with C-trap-stabilized HLA-E-VL9, HLA-E-RL9HIV, HLA-E-RL9SIV antigens.

931 After washing, antigen binding was detected by adding HRP-conjugated anti-human $\beta 2 \mathrm{M}$

932 antibody. (E) For SPR, biotinylated HLA-E-peptide complexes (HLA-E-VL9, HLA-E-RL9SIV,

933 HLA-E-RL9HIV and mock control) were bound to the immobilized streptavidin. Antibody $3 \mathrm{H} 4$

934 and control TE4 were flowed over sensor chips and antibody binding was monitored in real-

935 time.

936 


\section{A}
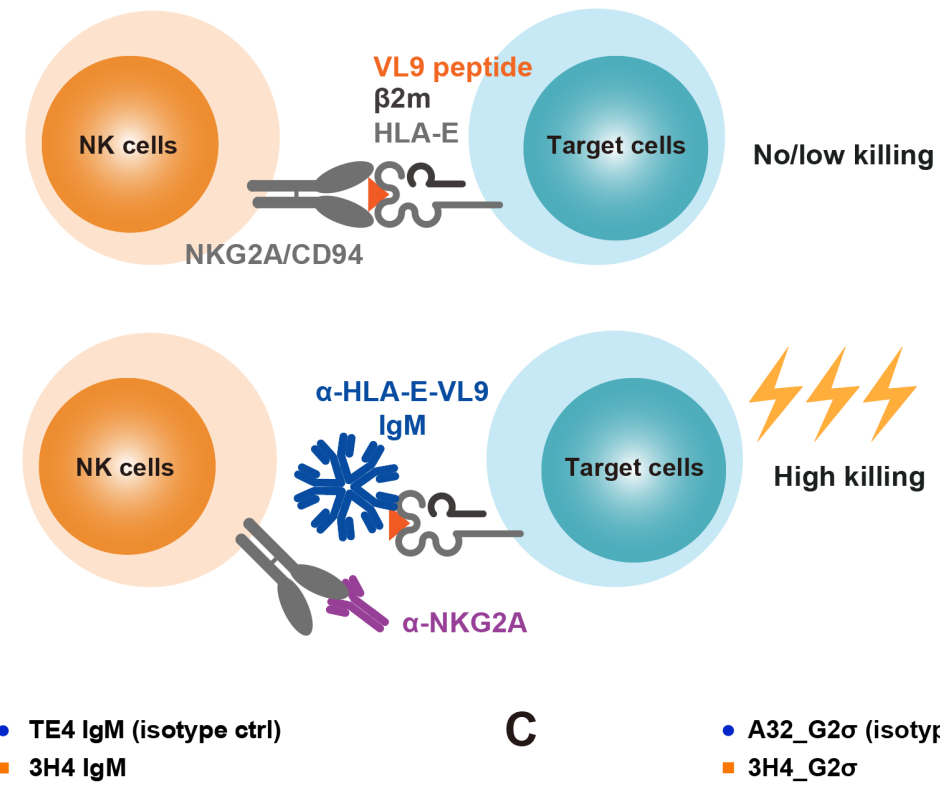

a.thaE:VIS

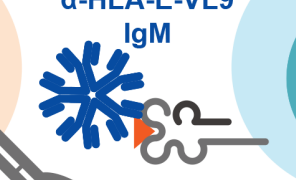

Target cells

High killing
B
- $3 \mathrm{H} 4 \lg M$

293T-HLA-E/VL9

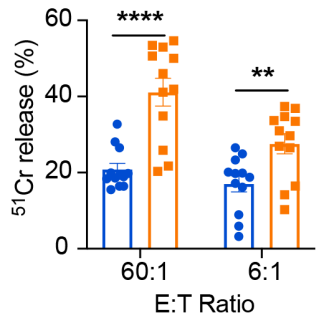

D

TE4 + Isotype ms IgG

- TE4 + anti-NKG2A (Z199)

293T-HLA-E-VL9

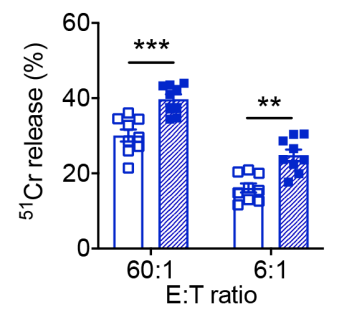

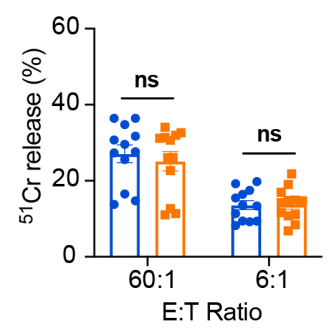

293T

293T

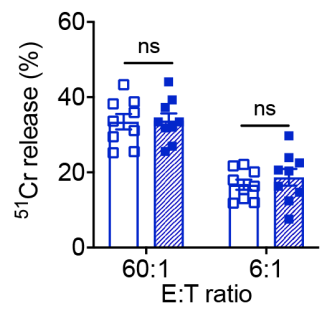

C A32_G2o (isotype ctrl)

293T-HLA-E-VL9

293T
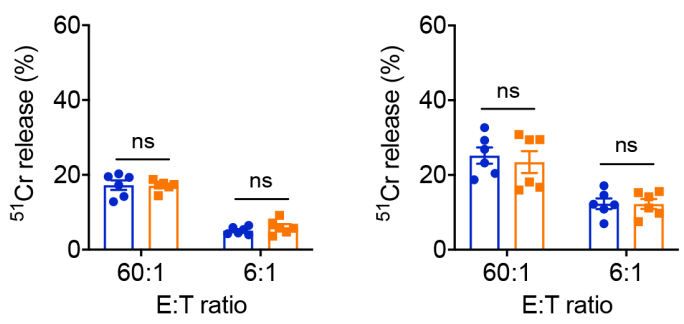

E $\quad \triangle 3 \mathrm{H} 4+$ Isotype ms $\lg \mathrm{G}$

$\triangle$ 3H4 + anti-NKG2A (Z199)

293T-HLA-E-VL9

293T
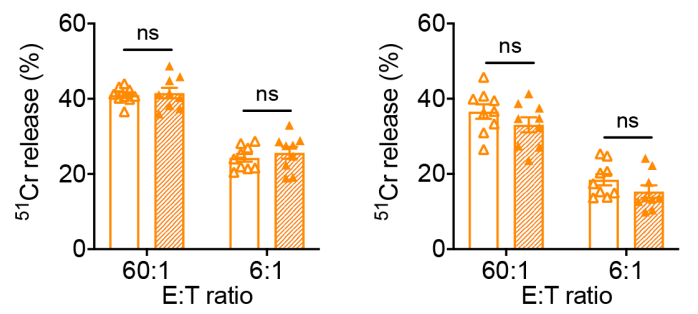

938 Figure 2. MAb 3H4 enhances cytotoxicity of a NKG2A+ NK cell line against HLA-E-VL9 expressing cells.

940 (A) Schematic graph of the hypothesis. Blockade of the inhibitory NKG2A/CD94/HLA-E

941 pathway with anti-HLA-E-VL9 antibody (3H4) and/or anti-NKG2A antibody (Z199) could

942 enhance target cell lysis by NK cells. 
943 (B-C) NK cell cytotoxicity against $3 \mathrm{H} 4 \mathrm{IgM}(\mathrm{B})$ or $3 \mathrm{H} 4 \mathrm{lgG}$ (C) treated target cells as

944 assessed by ${ }^{51} \mathrm{Cr}$ release assay. Antibody was incubated with HLA-E-VL9 transfected 293T

945 cells and untransfected 293T cells at final concentration of $10 \mu \mathrm{g} / \mathrm{ml}$, and NK92 cells were

946 added into the mixture as effector cells. Mouse IgM TE4 or human IgG A32_G2 $\sigma$ were used as

947 isotype controls. Dots represent all the data from four independent experiments, and bars show

948 mean \pm SEM.

949 (D-E) NK cell cytotoxicity in the presence of anti-NKG2A mouse IgG Z199 in combination

950 with TE4 control- or $3 \mathrm{H} 4-$ treated target cells as assessed by ${ }^{51} \mathrm{Cr}$ release assay. Antibody

951 combinations of Z199 + TE4 control (D) or Z199 + 3H4 (E) were incubated with HLA-E-VL9

952 transfected 293T cells and untransfected 293T cells at a final concentration of $10 \mu \mathrm{g} / \mathrm{ml}$, and

953 NK92 cells were added into the mixture as effector cells. Dots represent all the data from three

954 independent experiments, and bars show mean \pm SEM.

955 The $p$-values in all the panels were determined by Mann-Whitney $U$ tests. ${ }^{* * *}, p<0.0001 ;{ }^{* * *}$,

$9560.0001<p<0.001 ;{ }^{* *}, 0.001<p<0.01 ;$ ns, not significant. 

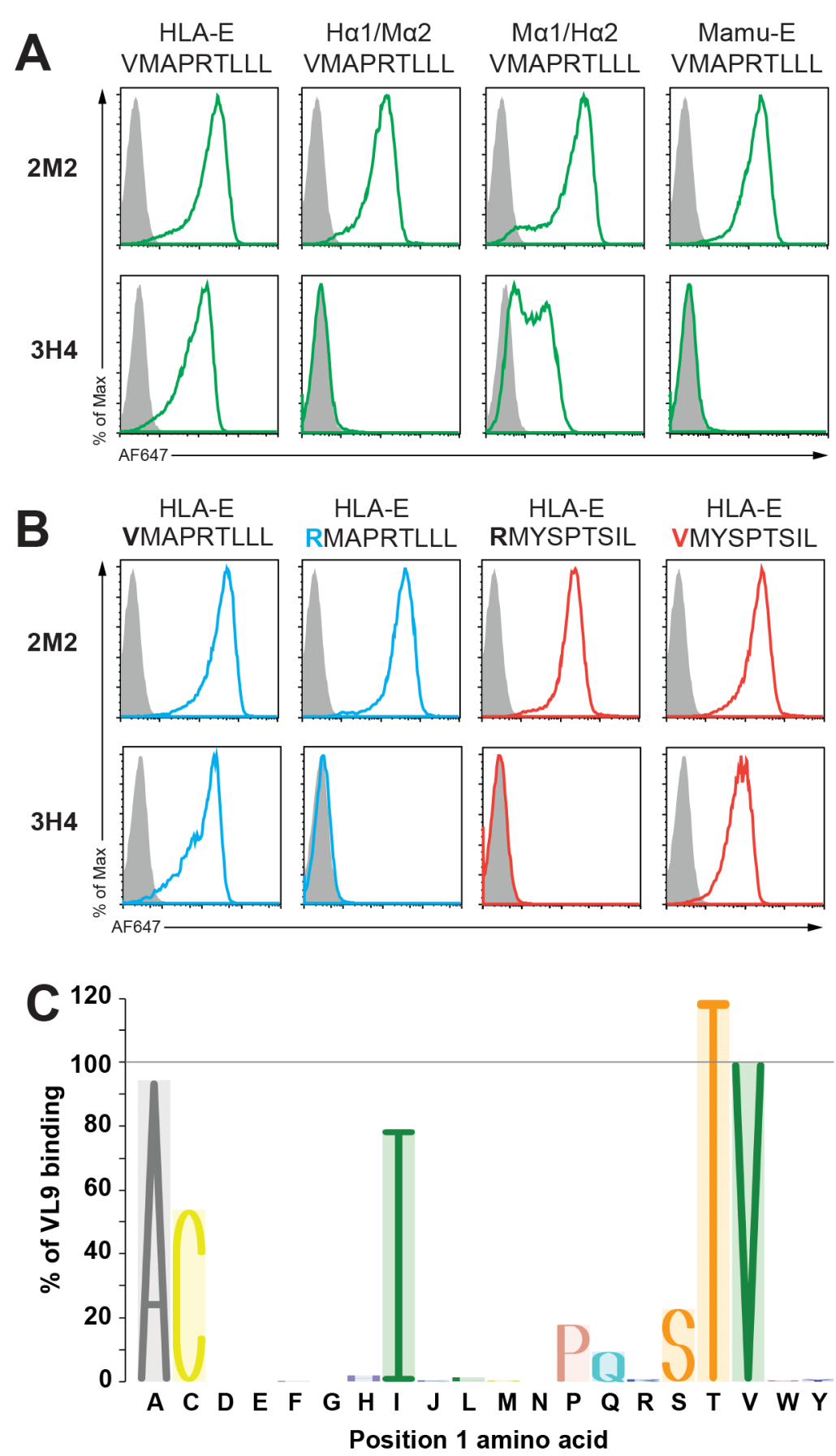

959 Figure 3. 3H4 recognition of both the HLA-E heavy chain $\alpha 2$ domain and the VL9 peptide.

960 (A) $3 \mathrm{H} 4$ recognizes the $\alpha 2$ domain of HLA-E. Flow cytometry analysis of $3 \mathrm{H} 4$ and 4D12 (HLA-

$961 \mathrm{E}$ mAb) binding to $293 \mathrm{~T}$ cells transfected with VL9 presented by HLA-E, Mamu-E, and two HLA-

962 E/Mamu-E hybrids - one with HLA-E a1/Mamu-E a2 (Ha1/Ma2), the other with Mamu-E

963 a1/HLA-E a2 (Ma1/Ha2) (green). Transfected cells were stained with testing antibody and then 
964 an AF647-anti-mouse $\lg (\mathrm{H}+\mathrm{L})$ secondary antibody. Isotype control stained cells were used as

965 negative controls (grey filled histograms).

966 (B) $3 \mathrm{H} 4$ recognizes position 1 (P1) of the VL9 peptide. $3 \mathrm{H} 4$ and $2 \mathrm{M} 2$ (a control $\beta 2 \mathrm{M} \mathrm{mAb}$ )

967 staining of 293T cells transfected with HLA-E-VL9 (VMAPRTLLL) or HLA-E-VL9 with a mutation

968 at P1 (valine to arginine; RMAPRTLLL) (blue), and with HLA-E-RL9HIV (RMYSPTSIL) or HLA-

969 E-RL9HIV with a mutation at P1 (arginine to valine; VMYSPTSIL) (red). Transfected cells were

970 stained with testing antibody and then an AF647-anti-mouse $\lg (\mathrm{H}+\mathrm{L})$ secondary antibody.

971 Isotype control stained cells used as negative controls (grey filled histograms).

972 (C) $3 \mathrm{H} 4$ recognizes peptides with variants in P1. 293T cells were transfected with HLA-E

973 SCTs with VL9 peptides with single amino acid mutations at P1, then stained with $3 \mathrm{H} 4$ antibody

974 followed by AF647 conjugated anti-mouse $\lg G(\mathrm{H}+\mathrm{L})$ secondary antibody. Cells were gated for

975 EGFP positive subsets. MFI of 3H4 staining on wildtype VL9 peptide was set as $100 \%$, and the

976 percentages equals to (MFI of $3 \mathrm{H} 4$ binding on each $\mathrm{P} 1$ variant) / (MFI of $3 \mathrm{H} 4$ binding on

977 wildtype VL9) $\times 100 \%$ 
bioRxiv preprint doi: https://doi.org/10.1101/2020.12 03.403014; this version posted December 3, 2020. The copyright holder for this preprint (which was not certified by peer review) is the author/funder, who has granted bioRxiv a license to display the preprint in perpetuity. It is made available under aCC-BY-NC-ND 4.0 International license.
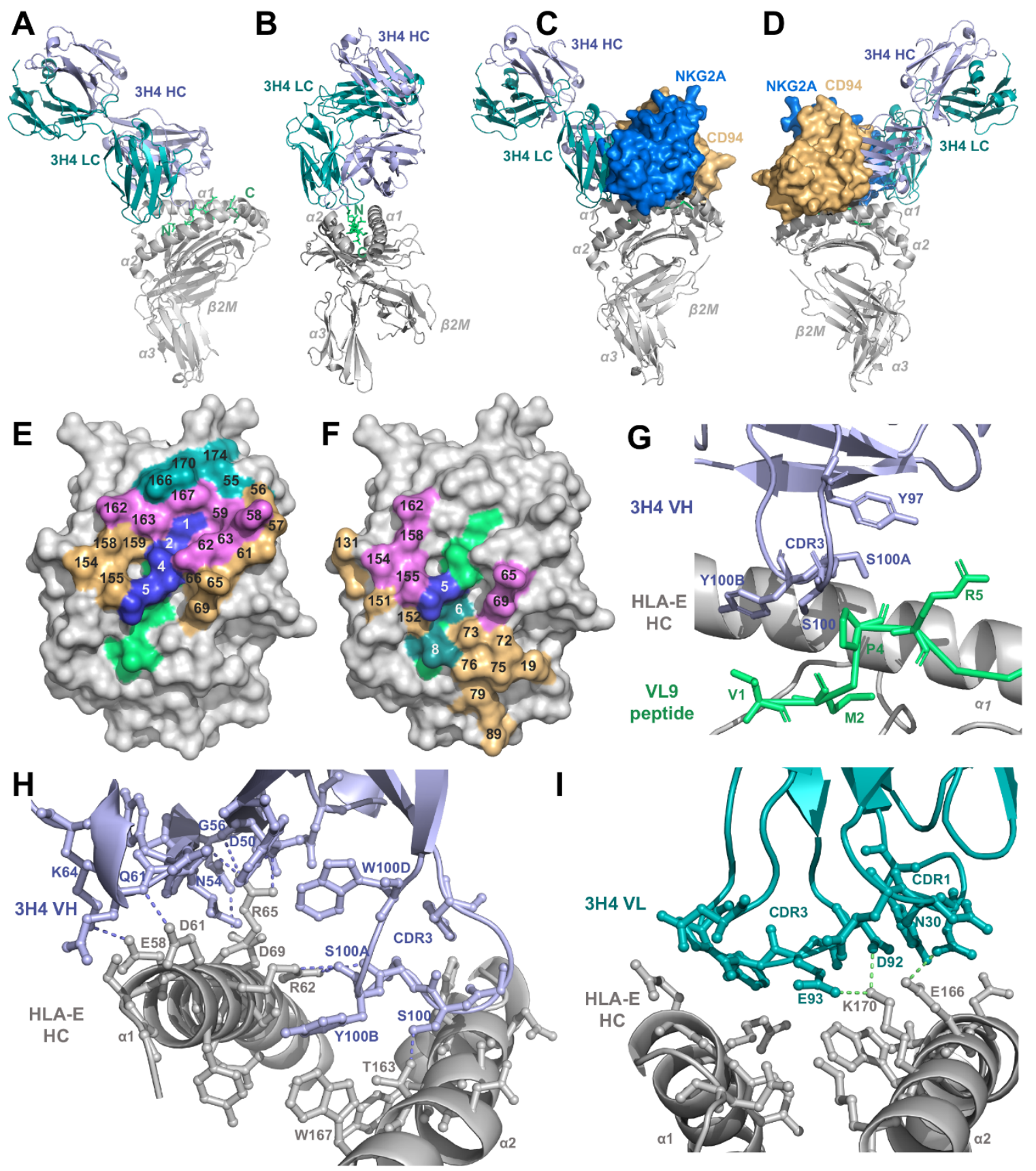

\section{J $>3 \mathrm{H} 4 \mathrm{HC}$}

EVQLQESGPELVKPGASVKIPCKASGYTFTDYNMDWVKQSHGKSLEW IGDINPNNGGTIYNQKFKGKATLTVDKSSSTAYMELRSLTSEDTAVYYC

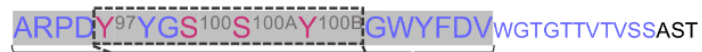
KGPSVFPLAPSSKST....

Germline-encoded D-segment key interfacing residues

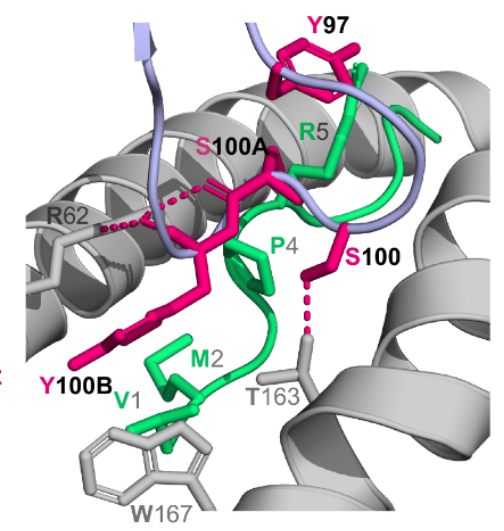


Figure 4. 3H4 Fab-HLA-E-VL9 co-complex structural visualisation.

980 (A-B) 3H4 Fab-HLA-E docking angles. The HLA-E heavy chain and $32 \mathrm{M}$ light chain are shown

981 as a grey cartoon, the VL9 peptide as lime green sticks, the $3 \mathrm{H} 4 \mathrm{HC}$ as a light purple cartoon

982 and the $3 \mathrm{H} 4$ light chain (LC) as a teal cartoon.

983 (C-D) Superposition of 3H4 Fab and CD94/NKG2A docking sites on HLA-E. The HLA-E

984 complex and 3H4 Fab are color-coded according to A and B. The CD94 subunit is shown as an 985 orange surface and the NKG2A subunit as a marine blue surface.

986 (E) Aerial view of the HLA-E-VL9 peptide binding groove surface. Non-interfacing residues

987 of the HLA-E heavy chain are shaded light grey and non-interfacing peptide residues shaded

988 lime green. VL9 peptide residues involved in the $3 \mathrm{H} 4$ interface are coloured marine blue.

989 Interfacing HLA-E HC residues that contact the $3 \mathrm{H} 4 \mathrm{VH}$ are shaded orange whereas those that 990 contact the $3 \mathrm{H} 4 \mathrm{VL}$ are shaded teal. HLA-E heavy chain residues involved in the interface with 991 both the $3 \mathrm{H} 4 \mathrm{VH}$ and VL are shaded violet. Residue positions are numbered on the HLA-E 992 surface view.

993 (F) Aerial view of the overlapping 3H4 and CD94/NKG2A footprints on the HLA-E peptide 994 binding groove. VL9 peptide residues involved in both the 3H4 and CD94/NKG2A interfaces 995 are shaded marine blue whereas HLA-E heavy chain residues involved in both interfaces are 996 shaded violet. Peptide and HLA-E heavy chain residues involved exclusively in the 997 CD94/NKG2A interface are shaded in teal and orange, respectively.

998 (G) Binding interface of 3H4 HC/VL9 peptide. Interfacing residues (Y97, S100, S100A and 999 Y100B of the VH CDR3 loop and V1, M2, P4 and R5 of the VL9 peptide) are shown in ball and 1000 stick-form with non-interfacing residues in cartoon form. The VL9 peptide is shaded lime green, 1001 the HLA-E heavy chain in grey and the $3 \mathrm{H} 4 \mathrm{HC}$ in light purple. $3 \mathrm{H} 4$ is numbered according to 1002 the Kabat scheme whereby alternate insertion codes (letters after the residue number) are 1003 added to variable length regions of the antibody sequence. Kabat numbering is applied in all 1004 subsequent figures. 
(H-I) Binding interfaces of 3H4 HC/HLA-E heavy chain (H) and 3H4 LC/HLA-E HC (I).

Interfacing residues are displayed in ball-and-stick form, non-interfacing residues are displayed

1007 in cartoon form and hydrogen bonds as dashed lines. In the 3H4 HC/HLA-E heavy chain

1008 interface $(H)$, interfacing residues derived from the HLA-E heavy chain (grey) include G56, S57,

1009 E58, Y59, D61, R62, E63, R65, S66 and D69 of the $\alpha 1$-helix and E154, H155, A158, Y159,

1010 D162, T163 and W167 of the a2-helix. 3H4 VH (light purple) interfacing residues include N33 of

1011 the CDR1 region, N52, N54, G56 and T57 of the CDR2 region, Y97, G99, S100, S100A, Y100B

1012 and W100D of the CDR3 region and W47, D50, I58, Y59, N60, Q61 and K64 of the non-CDR

1013 VH domain. In the 3H4 LC/HLA-E heavy chain interface (I), HLA-E heavy chain (grey)-derived

1014 interfacing residues include E55, E58, Y59 and R62 of the a1-helix and D162, T163, E166,

1015 W167, K170 and K174 of the a2-helix. 3H4 LC (teal) interfacing residues include Q27, D28, N30

1016 and $\mathrm{Y} 32$ of the CDR1 region, D92, E93, F94 and P95 of the CDR3 region in addition to D1 of

1017 the VL domain.

1018 (J) Key interfacing residues within the germline-encoded D-junction. 3H4 HC amino acid

1019 sequence with the VH segment in purple and the CDR1/2/3 regions shaded grey. Germline-

1020 encoded residues within the VH CDR3 D-junction are denoted. The 4 key interfacing residues

1021 (Y97, S100, S100A and Y100B) within this germline-encoded D-junction that make contacts

1022 with both the HLA-E heavy chain and VL9 peptide are highlighted magenta in the sequence and

1023 illustrated as magenta sticks in the PyMol visualisation. The HLA-E heavy chain and VL9

1024 peptide are displayed as grey and green cartoons, respectively, with key interfacing residues in

1025 stick form. Hydrogen bonds are depicted as magenta dashed lines and residues of the $3 \mathrm{H} 4 \mathrm{VH}$

1026 domain that are not germline-encoded key interfacing residues are displayed in light purple

1027 cartoon form.

1028 
bioRxiv preprint doi: https://doi.org/10.1101/2020.12.03.403014; this version posted December 3, 2020. The copyright holder for this preprint (which was not certified by peer review) is the author/funder, who has granted bioRxiv a license to display the preprint in perpetuity. It is made available under aCC-BY-NC-ND 4.0 International license.

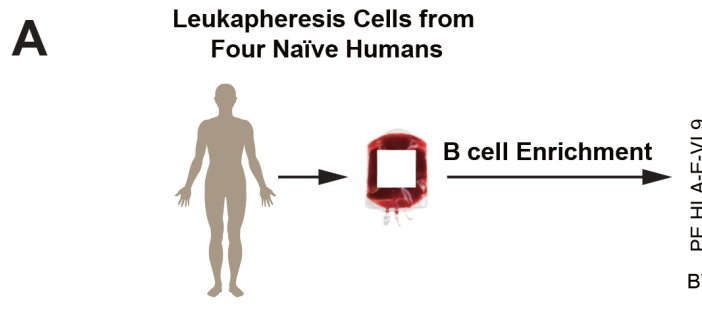

Differential Binding Screening on Transfected cells by HTS Flow Cytometry

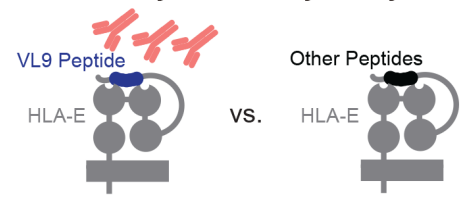

HLA-E-VL9-specific single B Cell Sorting

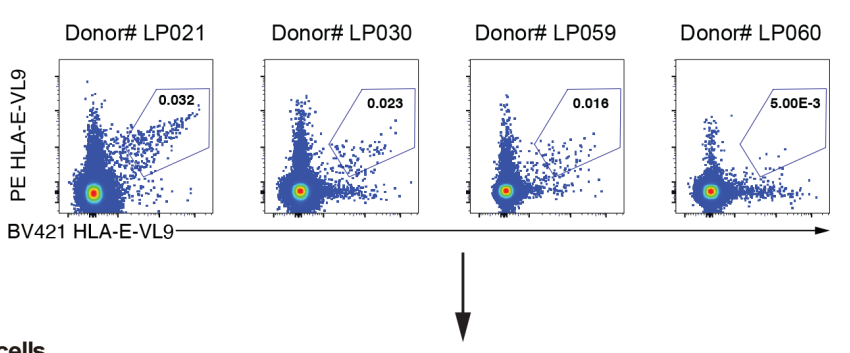

PCR, Cloning and MAb Production

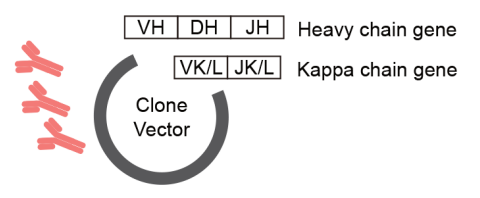

B

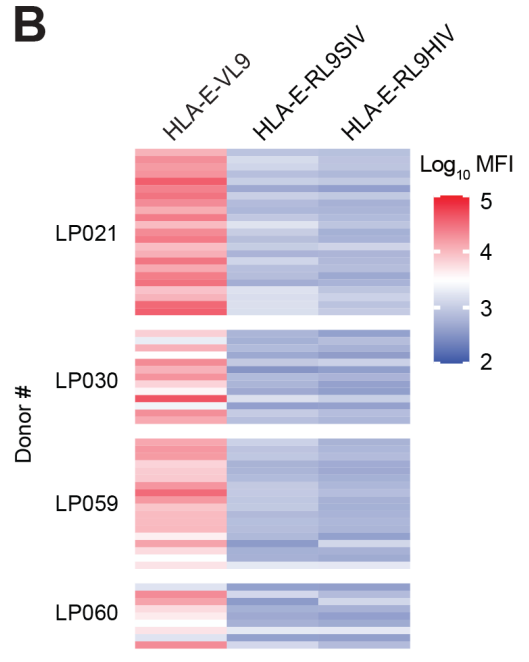

D

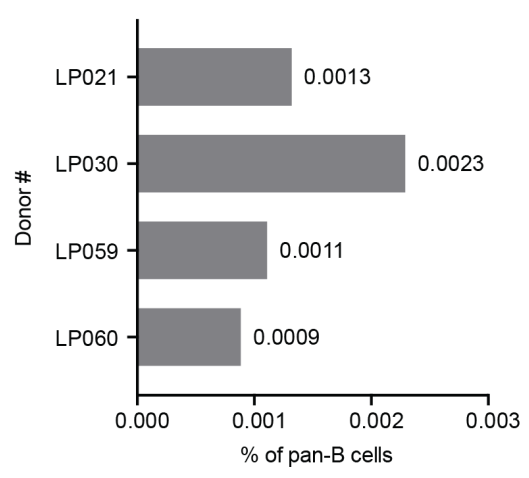

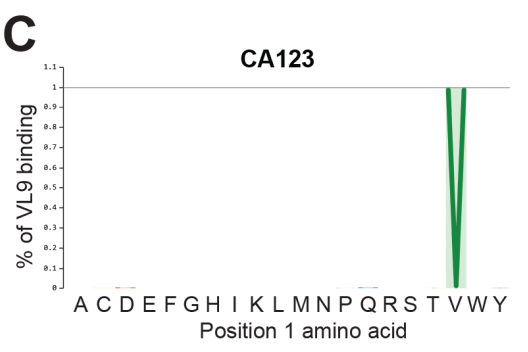
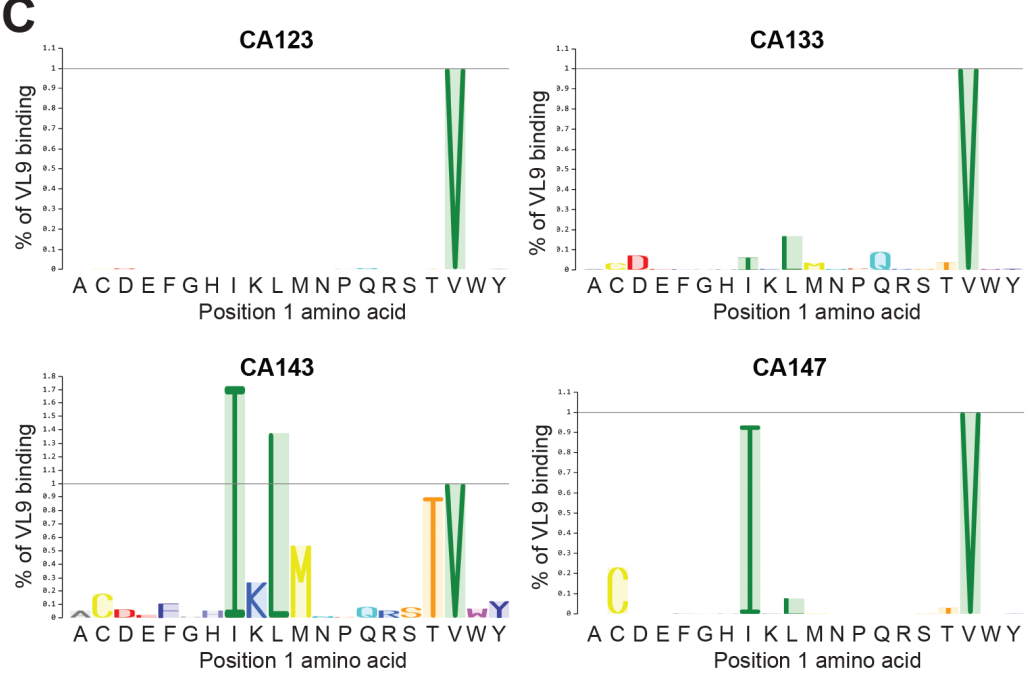

E

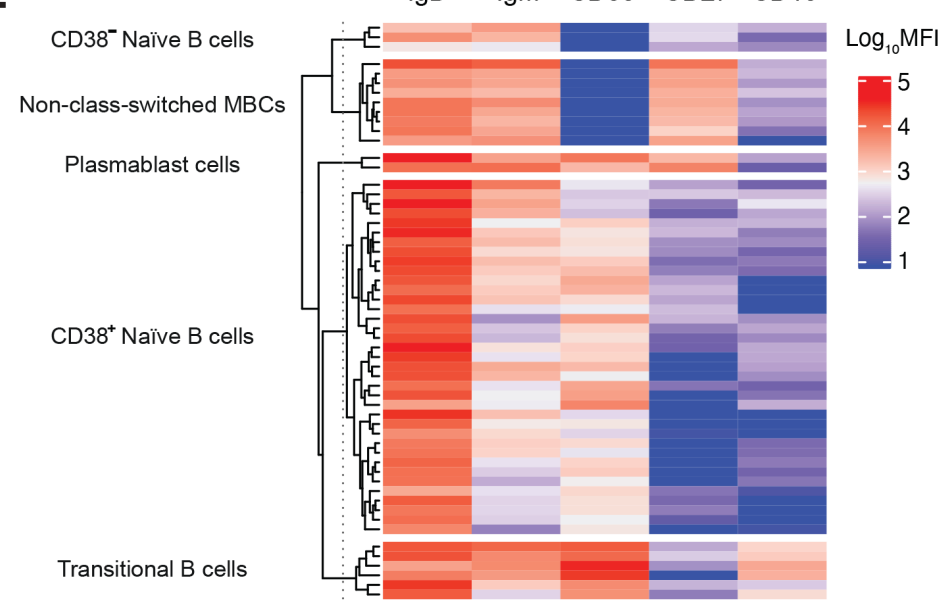

Figure 5. HLA-E-VL9-specific antibodies exist in the B cell pool of healthy humans. 
(A) Scheme of isolating HLA-E-VL9-specific antibodies from healthy humans. Pan-B cells were first isolated by negative selection from human leukapheresis PBMCs. A three-color

1033 sorting strategy was used to sort single B cells that were positive for HLA-E-VL9 and negative

1034 for HLA-E-RL9HIV or HLA-E-RL9SIV. Flow cytometry data showing the sorting of HLA-E-VL9

1035 double positive, HLA-E-RL9HIV negative, HLA-E-RL9SIV negative B cells in PBMCs from four

1036 donors (LP021, LP030, LP059 and LP060) are shown. Viable regions of antibody heavy and

1037 light chain genes were isolated from the sorted B cells by PCR, and constructed into an

1038 expression backbone with a human IgG1 constant region. Antibodies were produced by

1039 transient transfection in 293i cells, and antibody binding specificities were analyzed by surface

1040 staining of transfected 293T cells and high throughput screening (HTS) flow cytometry.

(B) Binding specificities of the HLA-E-VL9-specific antibodies ( $n=56)$ from four different

donors shown as a heatmap. The compensated MFIs of HLA-E-VL9-specific antibodies staining on transfected 293T cells at the concentration of $1 \mu \mathrm{g} / \mathrm{ml}$ were shown.

(C) Mapping of representative HLA-E-VL9-specific mAbs CA123, CA133, CA143 and

CA147 on 293T cells transfected with HLA-E-VL9 peptide variants. 293T cells were $100 \%$, and the percentages equals to (MFI of binding on each P1 variant) / (MFI of binding on 1051 wildtype VL9) x 100\%.

1052 (D) Percentage of HLA-E-VL9-specific B cells in CD19+ pan-B cells in four donors.

1053 (E) Phenotypes of HLA-E-VL9-specific B cells $(n=56)$ shown as heatmap. Expression of 1054 markers in each single B cell were determined from index sorting data and are shown as MFIs 1055 after compensation. Compensated MFIs below zero were set as zero. Each row indicates one 1056 single cell. The rows were clustered by K-means Clustering in R. Four subsets were observed: 
bioRxiv preprint doi: https://doi.org/10.1101/2020 12 03.403014 . this version posted December 3,2020 . The copyright holder for this preprint

(which was not certified by peer review) is the author/funder, who has granted bioRxiv a license to display the preprint in perpetuity. It is made available under aCC-BY-NC-ND 4.0 International license.

$1057 \mathrm{CD}^{-} \mathrm{C}^{-} \mathrm{CD} 27^{-} \mathrm{CD} 38^{+/-}$naïve $\mathrm{B}$ cells, $\mathrm{CD} 10^{+} \mathrm{CD} 27^{-} \mathrm{CD} 38^{++}$transitional $\mathrm{B}$ cells, $\mathrm{CD} 10^{-} \mathrm{CD} 27^{+} \mathrm{CD} 38^{-}$

1058 non-class-switched memory B cells, and CD $10^{-} \mathrm{CD} 27^{+} \mathrm{CD} 38^{+}$plasmablast cells. Detailed

1059 information for each single cell and antibody is shown in Table S6.

1060 


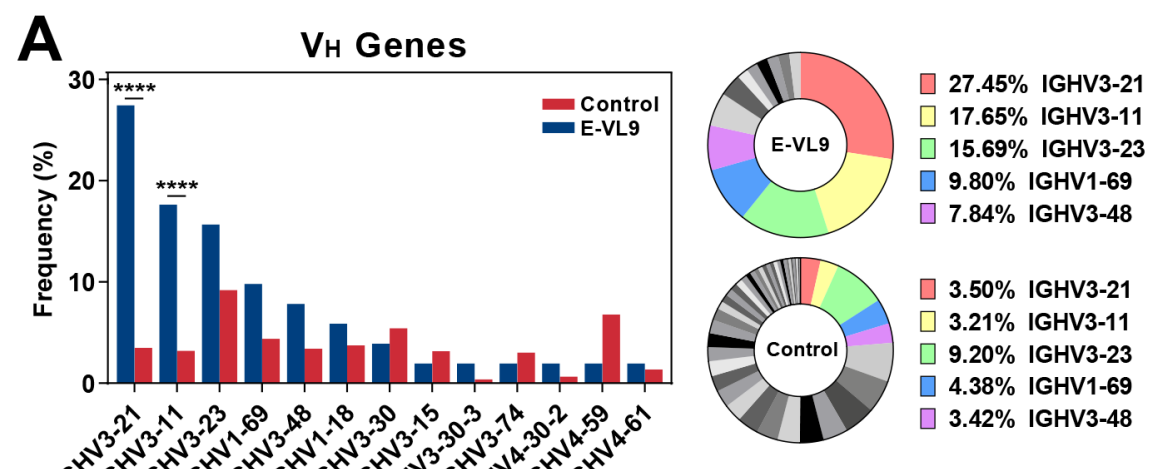

B
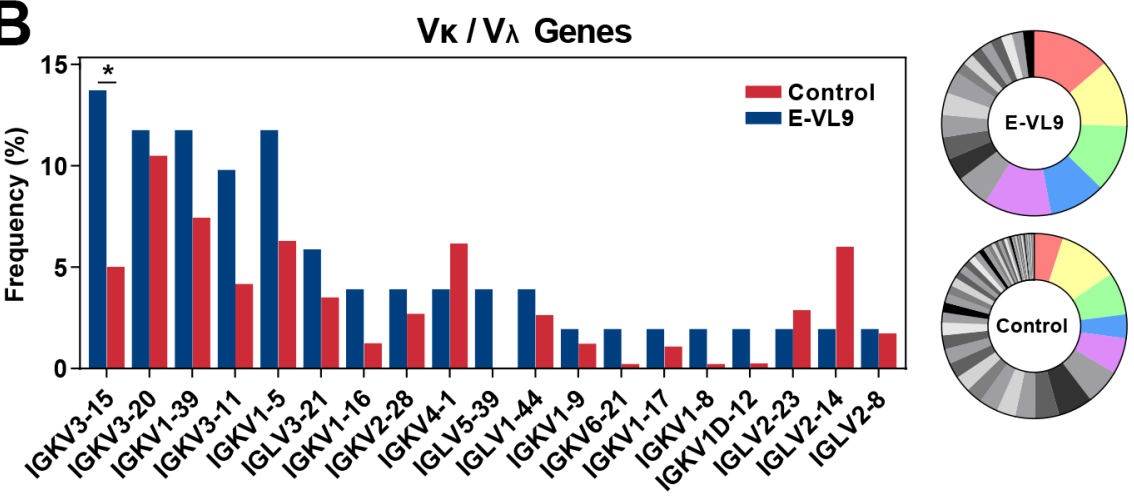

- 13.73\% IGKV3-15

$11.76 \%$ IGKV3-20

11.76\% IGKV1-39

प 9.80\% IGKV3-11

口 $11.76 \%$ IGKV1-5

$\square$ 5.02\% IGKV3-15

प $10.50 \%$ IGKV3-20

- 7.45\% IGKV1-39

$\square 4.18 \%$ IGKV3-11

6.31\% IGKV1-5
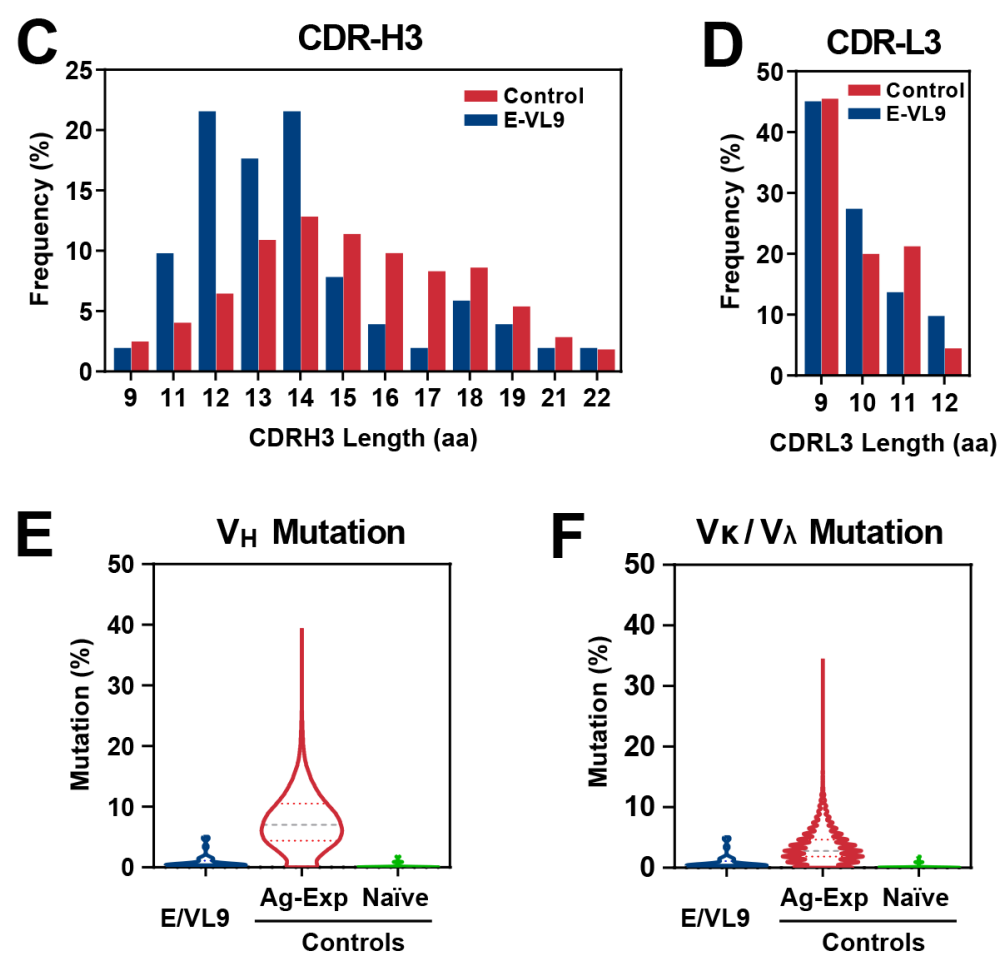

Figure 6. Sequence analysis of HLA-E-VL9-specific antibodies. HLA-E-VL9-specific

1063 antibody $(n=51)$ genes isolated from healthy humans were analyzed by Clonalyst and corrected 
1064 for clonality. Reference VH-VL repertoires $(n=198,148)$ from three healthy humans from a

1065 previous study (DeKosky et al., 2015) was used as a control for panels A-D Another set of

1066 reference sequences comparing naïve and antigen-experienced (Ag-Exp) antibody repertoires

1067 ( $n=13,780$ and 34,692, respectively) (DeKosky et al., 2016) was used as a control for panel E-F.

1068 The chi-square test of independence was performed to test for an association between

1069 indicated gene usage and repertoire/antibody type in panels A-B. ****, $p<0.0001$; *,

$1070 \quad 0.01<p<0.05$

1071 (A) Heavy chain viable $\left(V_{H}\right)$ region gene usage shown as a bar chart (left) and pie chart

1072 (right). The top five $V_{H}$ genes found in HLA-E-VL9-specific antibodies are colored in the pie

1073 charts.

1074 (B) Kappa chain variable $\left(V_{k}\right)$ and lambda chain variable $\left(V_{\lambda}\right)$ region gene usage shown as

1075 a bar chart (left) and pie chart (right). The top five $V_{K} / V_{\lambda}$ genes found in HLA-E-VL9-specific

1076 antibodies are colored in the pie charts.

1077 (C) Comparison of heavy chain CDR3 (CDR-H3) length.

1078 (D) Comparison of light chain CDR3 (CDR-L3) length.

1079 (E-F) Violin plots showing the mutation rates of heavy chains $(\mathrm{H})$ and light chains (I). 
RLPAKAPLL (Mtb44 Control) VMPPRALLL (Escherichia coli MS 176-1) VMAGRTLLL (Stenotrophomonas sp.) VMAPRTKLL (Pseudomonas formosensis) RMSPRTLLL (Mycobacterium bohemicum) KMAPRSLLL (Proteobacteria) LMAPKTLLL (Lentisphaerae) GMAPRSLLL (Massilia sp.)

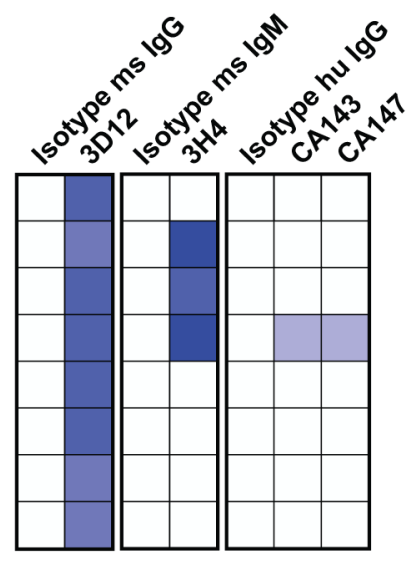

Relative MFI

(to no peptide control)

$>5000$

$3001-6000$

$1001-3000$

$600-1000$

$<600$

1083 Figure 7. HLA-E-VL9-specific antibodies cross-react with certain microbiome-derived

1084 peptides presented by HLA-E. K562 cells loaded with microbiome-derived peptides were

1085 stained with the indicated antibodies at a concentration of $10 \mu \mathrm{g} / \mathrm{ml}$. Binding activities are shown

1086 in heatmap form with relative MFIs (MFI of peptide-loaded cells minus MFI of no peptide control

1087 cells) depicted on the scale shown. 